\title{
Temporal stability of surface soil moisture of different vegetation types in the Loess Plateau of China
}

\author{
Ji Zhou $^{\text {a,b }}$, Bojie Fu ${ }^{\text {a,b,* }}$, Guangyao Gao ${ }^{\text {a,b }}$, Nan Lü ${ }^{\text {a,b }}$, Yihe Lü ${ }^{\text {a,b }}$, Shuai Wang a,b \\ a State Key Laboratory of Urban and Regional Ecology, Research Center for Eco-Environmental Sciences, Chinese Academy of Sciences, Beijing 100085, PR China \\ b Joint Center for Global Change Studies, Beijing 100875, China
}

\section{A R T I C L E I N F O}

\section{Article history:}

Received 9 October 2014

Received in revised form 14 January 2015

Accepted 17 January 2015

Available online 23 January 2015

\section{Keywords:}

Temporal stability

Soil moisture

Vegetation type

Hydrological processes

\begin{abstract}
A B S T R A C T
The temporal stability of soil moisture (TSSM) was widely applied to optimize the soil moisture sampling scheme on a catchment or even larger spatial scale over wet and dry observational periods. However, the integration of the TSSM feature with specific hydrological response at a small plot scale has not been sufficiently researched. This study analyzed the temporal stability of surface soil moisture $(0-10 \mathrm{~cm})$ characteristics and corresponding influencing factors of different vegetation types under two typical soil moisture changing processes including wet-to-dry (WTD) and dry-to-wet (DTW), and determined the representative points. A total of 16 microplots $(60 \times 60 \mathrm{~cm}$ each) that were composed of three vegetation types containing Andropogon, Artemisia scoparia and Spiraea pubescens and bare land cover were selected. And the soil moisture in the central point (CP) and four ambient points (APs) of each microplot were measured during the WTD and DTW processes. The results showed that, 1) from DTW to WTD processes, the distribution of the soil water content in different vegetation types indicated a significant difference. Compared with the soil moisture in the AP or CP area of other vegetation types, the soil water content in tall shrub types (S. pubescens) was the lowest. 2) The autocorrelation coefficient indicated that both in the AP and CP areas, the soil moisture of the low shrub types (A. scoparia) had a higher temporal stability than that of other vegetation types. However, the soil water content in bare land had the highest temporal fluctuation from the DTW to WTD processes. Additionally, in the CP area, the TSSM of all the vegetation types tended to decrease during the WTD process. 3) Based on the TSSM analysis system that was derived from the principle of probability and statistics, the soil moisture in the low shrub types (A. scoparia) most likely provides the best representativeness of the spatial average soil water content of heterogeneous vegetation types. The determination of the representative soil moisture point via the hydrological-trait sampling method could be supplementary and significant for a TSSM study of the available soil water resources in an arid and semi-arid ecosystem.
\end{abstract}

(C) 2015 Elsevier B.V. All rights reserved.

\section{Introduction}

Soil moisture is an indispensable stress factor in water-controlled ecosystems (Noy-Meir, 1973). In arid and semi-arid environments, the distribution of soil moisture over a specific observational period has often been studied on many different spatial scales (Bell et al., 1980; Brocca et al., 2010; Lin et al., 2006; Qiu et al., 2001), which have a farreaching impact on the runoff and sediment generation (Calvo-Cases et al., 2003; Fitzjohn et al., 1998), the dynamic balance of water in the soil-plant-atmosphere continuum of different vegetation types (Rodriguez-Iturbe et al., 2001), and the utilization of available water resources in arid and semi-arid ecosystems. In fact, the complex influencing factors of soil moisture response indicated that the soil water has a high variability at different spatiotemporal scales. As a result, a comprehensive analysis of the variable spatiotemporal

\footnotetext{
* Corresponding author at: P.O. Box 2871, Beijing 100085, China.

E-mail address: bfu@rcees.ac.cn (B. Fu).
}

characteristics of soil moisture is necessary to understand the behavior of soil water in arid and semi-arid environments. Under this background, the concept of the temporal stability of soil moisture (TSSM) was proposed by Vachaud et al. (1985), and was defined as the time invariant association between the spatial location and statistical parametric values based on the probability density function of the soil moisture.

TSSM specifically indicates that the order of the soil moisture or of the average soil moisture arranged in the spatial pattern does not fluctuate with the observational period (Kachanoski and de Jong, 1988). The succession of the interval observation period, the homogeneity of the spatial distribution of soil moisture, and the coupling of the spatial and temporal patterns of the soil water content constituted the main elements of TSSM research. First, different spatial scales of TSSM studies were systemically investigated by many researchers. These scales ranged from multiple investigated fields scales (300 $\mathrm{m}^{2}$ per field) (Brocca et al., 2010) to hillslope scales (approximately $900 \mathrm{~m}^{2}$ ) (Coppola et al., 2011; Penna et al., 2013), from watershed scales (610 $\mathrm{km}^{2}$ and $1285 \mathrm{~km}^{2}$ respectively) to an even larger landscape 
scale (Martinez-Fernandez and Ceballos, 2003; Starks et al., 2006). In the Loess Plateau, many researchers (Gao and Shao, 2012; Hu et al., 2010; Jia and Shao, 2013) have also investigated the TSSM in different watersheds.

Second, aiming to analyze the TSSM characteristics under extreme soil water conditions, the temporal pattern of soil moisture initially focused on two different observation periods representing the wet and dry soil moisture conditions (Grayson and Western, 1998; Grayson et al., 1997). For instance, Penna et al. (2013) systematically reported the TSSM characteristics of different soil depths under hillslope scales during the wet and dry periods in the three years. Heathman et al. (2012) divided the temporal pattern of soil moisture into three patterns-time-averaged, wettest and driest period-and mutually compared corresponding TSSM characteristics at field scale. Other researchers (Brocca et al., 2010; Gomez-Plaza et al., 2000; Williams et al., 2009) also analyzed the TSSM in the wet and dry periods on watershed and landscape scales. However, the TSSM characteristics in the two temporal patterns under different spatial scales are still debatable (Gomez-Plaza et al., 2000; Martinez-Fernandez and Ceballos, 2003; Williams et al., 2009; Zhao et al., 2010), because the main influencing factors of the TSSM-such as topography (Brocca et al., 2007, 2009), soil texture (Cosh et al., 2006; Gao and Shao, 2012;
Porporato et al., 2001; Starks et al., 2006), precipitation and vegetation types (Brocca et al., 2009; Jia and Shao, 2013; Mohanty and Skaggs, 2001)-are complicated and vary with the spatial scale.

Third, based on the principle of probability and statistics, Vachaud et al. (1985) introduced a series of indices into the TSSM calculation system that could quantify the TSSM characteristics. Mittelbach and Seneviratne (2012) indicated that the rank stability index could be the best way to characterize the temporal stability pattern through relative long-term measurement of soil moisture. And other TSSM evaluation indices contain the cumulative probability, autocorrelation coefficient, and mean/standard deviation of relative differences, which were derived from the probability density function, time series analysis, and statistical inference respectively. Moreover, other researchers (Jacobs et al., 2004; Penna et al., 2013; Zhao et al., 2010) further integrated these statistical methods and defined the index of temporal stability. And some new mathematical tools were also used to analyze the TSSM, such as the combination of climate simulation with TSSM characteristics (Matinez et al., 2014), geostatistical method (Brocca et al., 2009), spatial autocorrelation technique (Biswas and Si, 2011) and wavelet coherency analysis algorithm. The integration of these TSSM analysis methods and remote sensing technique could effectively promote the precision of the soil moisture estimation at large spatial scales (a)
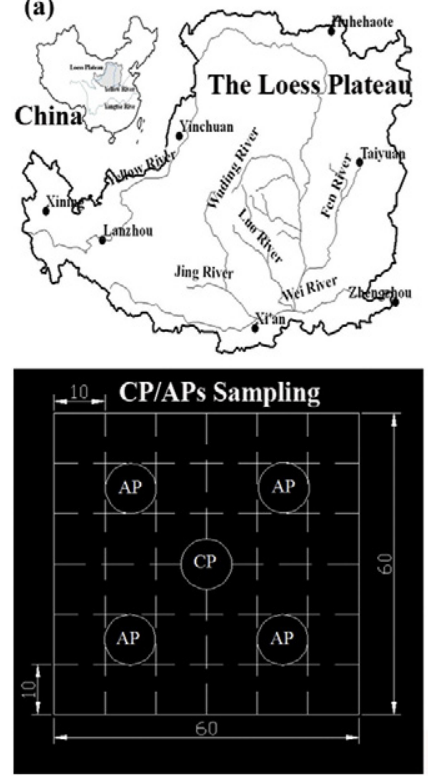

The Yangjuangou Catchment

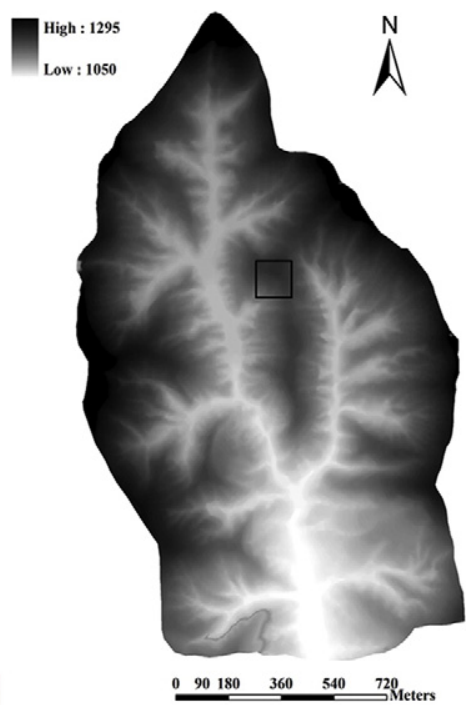

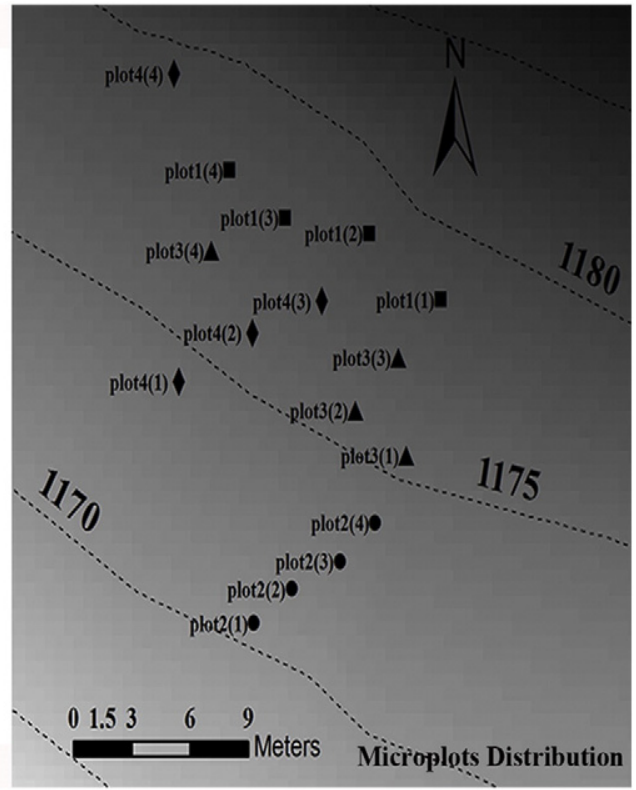

(b)

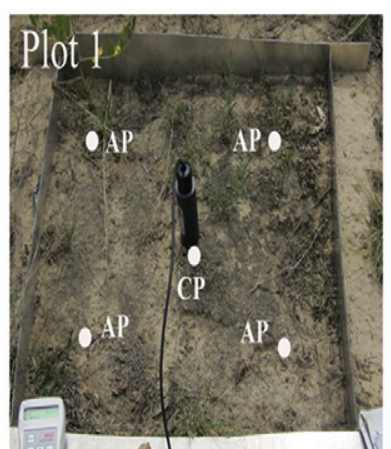

Bare Land

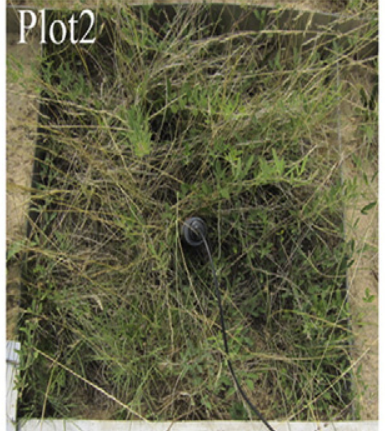

Andropogon

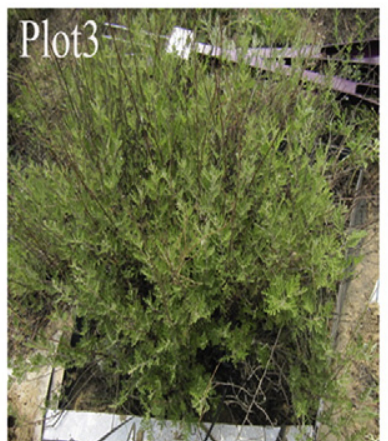

Artemisia scoparia

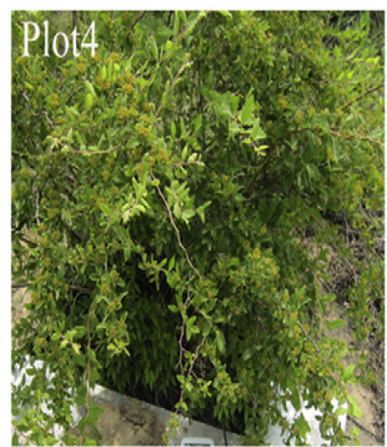

Spiraea pubescens

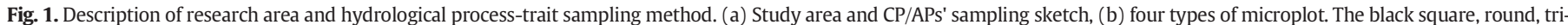

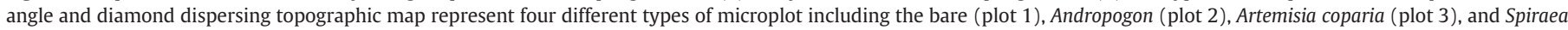

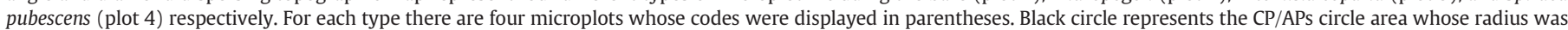
near $5-8 \mathrm{~cm}$. 
Table 1

Soil characteristics of four microplot types.

\begin{tabular}{llllll}
\hline Types & $\begin{array}{l}\text { Plot } \\
\text { code }\end{array}$ & Clay (\%) & Silt (\%) & Sand (\%) & $\begin{array}{l}\mathrm{BD} \\
\left(\mathrm{g} \cdot \mathrm{cm}^{-3}\right)^{\mathrm{a}}\end{array}$ \\
\hline $\begin{array}{l}\text { Bare } \\
\text { Andropogon }\end{array}$ & Plot 1 & $9.21 \pm 1.21$ & $26.04 \pm 2.41$ & $64.75 \pm 1.85$ & $1.24 \pm 0.09$ \\
$\begin{array}{c}\text { Artemisia } \\
\quad \text { coparia }\end{array}$ & Plot 3 & $9.48 \pm 2.14$ & $25.28 \pm 1.98$ & $66.24 \pm 2.24$ & $1.26 \pm 0.11$ \\
$\begin{array}{c}\text { Spiraea } \\
\text { pubescens }\end{array}$ & Plot 4 & $11.98 \pm 3.15$ & $26.72 \pm 2.87$ & $63.74 \pm 3.24$ & $1.13 \pm 0.10$ \\
\hline
\end{tabular}

${ }^{\text {a }}$ Means average soil dry bulk density.

(Jacobs et al., 2004; Martinez-Fernandez and Ceballos, 2003; Mohanty and Skaggs, 2001). Therefore, the application of TSSM-based sampling method, the determination of the temporal pattern of soil moisture, and the construction of the TSSM calculation system were all the preparation for determination of representative soil moisture points or locations. This representativeness could effectively reflect the mean soil water content in a specific study area during the successive observational interval (Grayson and Western, 1998). Many studies (Vachaud et al., 1985; Van Pelt and Wierenga, 2001) have demonstrated that the application of the TSSM analysis system to determine representative points successfully optimized the spatial sampling points of the soil moisture and reduced the uncertainty of the soil water distribution estimation at different study regions. However, in a previous TSSM study, two types of soil moisture uniform sampling strategies including gridding and network sampling methods were used. The uniform configuration of the soil moisture monitoring points probably neglected the information about the diversity of vegetation type distribution in different land uses, as well as the corresponding impact on TSSM characteristics. Moreover, because of the temporal scale of TSSM in previous studiessuch as time-averaged, wet and dry periods of soil moisture-being relative coarse, the relationship between specific hydrological response including dry to wet (DTW) condition or wet to dry (WTD) condition processes and the corresponding TSSM characteristics has not been sufficiently analyzed.

Therefore, this study combined WTD or DTW processes with corresponding TSSM characteristics, which could be beneficial to exploring and understanding the TSSM feature of heterogeneous vegetation distribution on a specific hillslope. We aimed to 1): evaluate the temporal pattern of soil moisture in different types of microplot over WTD and DTW processes affected by the integration of precipitation and radiation; 2): analyze the different soil moisture responses of vegetation types on WTD and DTW processes through using the hydrological process-trait sampling method; and finally 3 ): analyze the influence of different vegetation types on the corresponding TSSM during WTD and DTW processes by determining the representative points which reflect the mean soil water content in a specific hillslope. All of these contents could provide supplemental research concerning the temporal characteristics of the available soil water resources in a water-limited

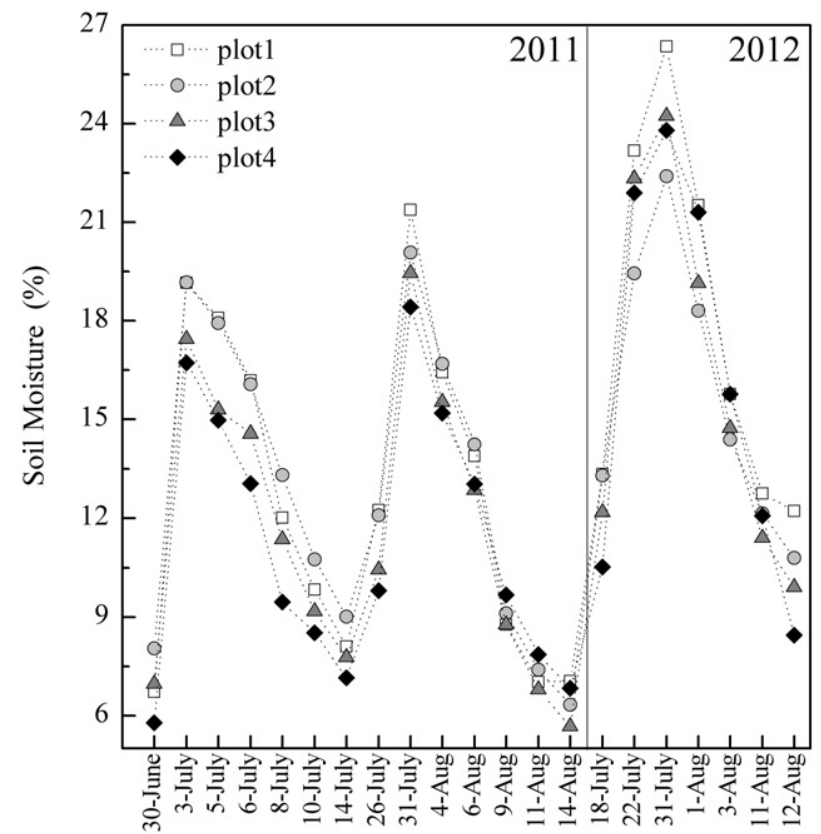

Fig. 2. Long time average soil moisture dynamics of four microplot types in rainy seasons.

ecosystem. These findings could be beneficial to understanding hydrological mechanisms from the TSSM point of view and be significant for evaluating the influence of vegetation layout on the use of available water resources in water-controlled ecosystems through challenging issues of interdisciplinary research fields that are related to soil moisture.

\section{Materials and methods}

\subsection{Description of study area}

The experiment was conducted in the Yangjuangou Catchment $\left(36^{\circ} 42^{\prime} \mathrm{N}, 109^{\circ} 31^{\prime} \mathrm{E}, 2.02 \mathrm{~km}^{2}\right)$ site in the central part of the Loess Plateau (Fig. 1a). The elevation of this site ranges from $1050 \mathrm{~m}$ to $1298 \mathrm{~m}$, and the slope gradient mainly fluctuate between $17.6 \%$ and $57.7 \%$. The precipitation is influenced by North China monsoon, distributes significant inter-annual differences, occurs between June and September and totals approximately $535 \mathrm{~mm}$ per year (Gao et al., 2012). The soil type in the catchment is Loessal soil, which has a weak structure and high erosion sensitivity (Gao and Shao, 2012; Li et al., 2003; Wang et al., 2009). The main soil characteristics of the microplots are shown in Table 1. The dominant vegetation types include Stipabungeana (Andropogon), Hippophae rhamnoides, Artemisia scoparia, Spiraea pubescens and Prunus armeniaca var. ansu (Shao et al., 2010). We designed 16 square microplots $(60 \times 60 \mathrm{~cm}$ for each $)$ including bare

Table 2

Morphological characteristics of vegetation microplots.

\begin{tabular}{|c|c|c|c|c|c|c|c|c|c|c|}
\hline Dominant plant & Plot code & Height $(\mathrm{cm})^{\mathrm{a}}$ & $\mathrm{LS}(\mathrm{cm})^{\mathrm{b}}$ & Crown $(\mathrm{cm})^{\mathrm{c}}$ & Coverage (\%) ${ }^{\mathrm{d}}$ & $\mathrm{LAI}^{\mathrm{e}}$ & Biomass $\left(g \cdot m^{-2}\right)^{f}$ & $\mathrm{LL}(\mathrm{cm})^{\mathrm{g}}$ & $\mathrm{SC}(\%)^{\mathrm{h}}$ & Year $^{\mathrm{i}}$ \\
\hline Bare & Plot 1 & 0 & 0 & 0 & 0 & 0 & 0 & 0 & $<5$ & \\
\hline Andropogon & Plot 2 & 32.4 & 0 & 0 & $70-85$ & 1.22 & $68.9 / 137.2$ & 0 & 0 & 20 \\
\hline Artemisia coparia & Plot 3 & 61.8 & 0 & 64.3 & $90-100$ & 1.78 & $218.5 / 677.6$ & 1.8 & 0 & 20 \\
\hline Spiraea pubescens & Plot 4 & 128.3 & 46.7 & 80.6 & 100 & 2.31 & $423.4 / 2136.1$ & 3.4 & 0 & 20 \\
\hline
\end{tabular}

a Means average height of single plant.

b Means average length of obvious stem only owned by Spiraea pubescens (plot 4).

c Means that average crown width only existed in Artemisia coparia (plot 3) and Spiraea pubescens (plot 4).

d Means the range of coverage in three vegetated microplots.

e Means leaf area index.

${ }^{f}$ Means average aboveground biomass/underground biomass of corresponding similar vegetation which was in the $60 \times 60 \mathrm{~cm}$ area.

g Means the average thickness of litter layer covering on surface of corresponding microplot.

h Means the ratio of the average biological soil crust area to microplot area only existed in bare land.

${ }^{\mathrm{i}}$ Means the revegetation years. 
land cover (plot 1), and for another three vegetation types, the dominant plant communities are Andropogon (plot 2), A. scoparia (plot 3), and S. pubescens (plot 4). The morphological characteristics of vegetation were shown in Table 2, which describes the main statistical features of the plant. Under the background of the Grain-for-Green Project implementation in the 1980s, nearly all of the intensive-humandisturbed croplands on hillslopes, in the Yangjuangou catchment, had been returned to vegetation land which effectively prevented soil erosion. All of the vegetation in the microplots that was revegetated in the 1980s had grown for 20 years in the catchment. All microplots were randomly distributed on a 30 -meter-long southwest-northeast aspect $26.8 \%$ heterogeneous vegetation hillslope (approximately $600 \mathrm{~m}^{2}$ ). Each microplot including one single plant was fenced by four impervious PVC sheets with a thickness of $2 \mathrm{~mm}$ and width of $800 \mathrm{~mm}$. All the sheets were perpendicularly inserted into soil layer down to a depth of approximately $50 \mathrm{~cm}$. We focused on the TSSM in the surface soil layer $(0-10 \mathrm{~cm})$, therefore, the inserted PVC sheets could effectively prevent the soil water from generating lateral diffusion, which probably reduced the impact of the lateral effect on the accuracy of the soil moisture.

\subsection{Hydrological process-trait sampling method}

In order to compare the TSSM characteristics of the three vegetation types in different locations of microplot, we classified the soil moisture measurement points into the central point (CP), and ambient points (APs) as shown in Fig. 1b. The CP/APs' classification concerning the different influences of the vegetation morphology on WTD and DTW processes could be regarded as the hydrological process-trait sampling method. The TDR-300 Soil Moisture Meter (Spectrum Technologies, Inc, Aurora, Illinois, USA) was used to measure the soil volumetric water content in $0-10 \mathrm{~cm}$ depth soil layer. Two types of vegetation microplots (plot 3 and plot 4) have complex canopy structures that make the use of the $\mathrm{CP} / \mathrm{AP}$ method more difficult than that of bare

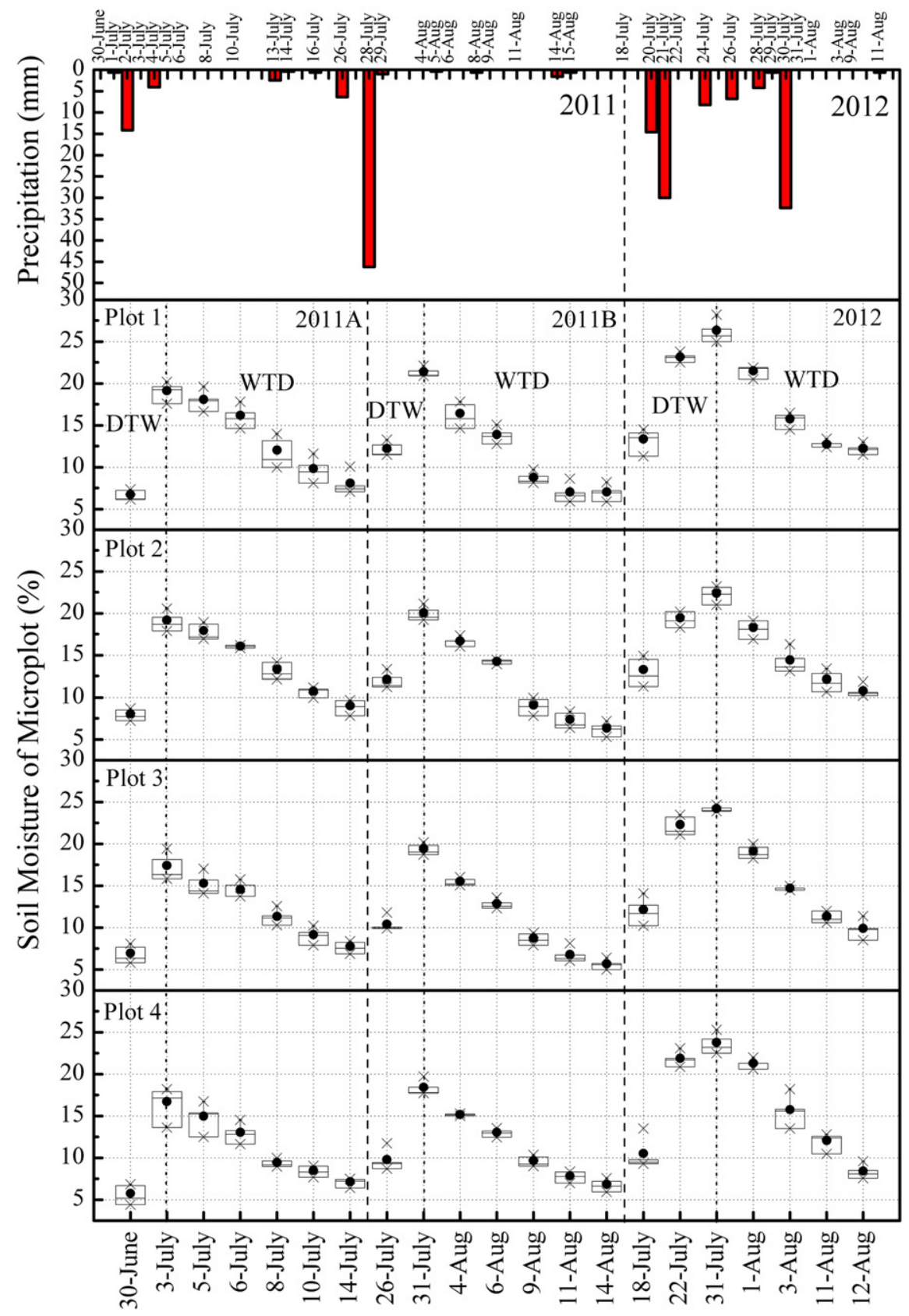

Fig. 3. Precipitation and soil moisture distribution of different types of microplot over three soil moisture responses. 
(plot 1) and grass (plot 2) types. Therefore, before measuring in these vegetation microplots, the first step was to determinate the $\mathrm{CP}$ and $\mathrm{AP}$ sampling areas that were characterized as circle areas of radius $5-8 \mathrm{~cm}$ (Fig. 1a). This step could reduce the probability of the TDR probes touching the main root or the huge soil pores that were formed by the main roots in the $\mathrm{CP}$ position throughout the measuring processes. It also could prevent the probes of the TDR from repeatedly disturbing the same point. The second step was to softly remove the litter layer covering over the surface of the $\mathrm{CP}$ and APs circle area of plot 3 and plot 4 with a brush before measurement. When the logging-data process was finished, every disturbed hole that was caused by probes was carefully filled with fine soil particles, after which the litter layer on the CP or APs circle area was recovered.

\subsection{TSSM analysis system}

\subsubsection{Determination of the temporal pattern}

Temporal pattern of soil moisture consists of two typical processes. One is DTW process influenced by precipitation events, and the other process is the WTD process affected by continuous high temperature events; the average time interval of soil moisture measurement in the temporal pattern is two days. Each of the process composes an entire typical soil moisture response or pulse (Eagleson, 1978a). We selected three typical soil moisture responses to analyze the TSSM characteristics in $\mathrm{CP}$ and APs' sampling areas.

\subsubsection{The calculation of the TSSM by statistics}

The TSSM calculation system consists of four indices including mean relative difference, standard deviation, temporal stability index, and cumulative probability distribution. All the indices describe the statistical properties of TSSM. Regarding the CP area, the mean relative difference of TSSM (TSSM-MRD) was calculated as follows:

$$
\begin{aligned}
& \bar{\theta}_{C P(* \cdot j)}=\frac{\sum_{i=1}^{16} \theta_{C P(i, j)}}{16} \\
& \Delta_{C P(i . j)}=\theta_{C P(i, j)}-\bar{\theta}_{C P(* \cdot j)} \\
& \delta_{C P(i, j)}=\frac{\Delta_{C P(i, j)}}{\theta_{C P(* \cdot j)}}
\end{aligned}
$$

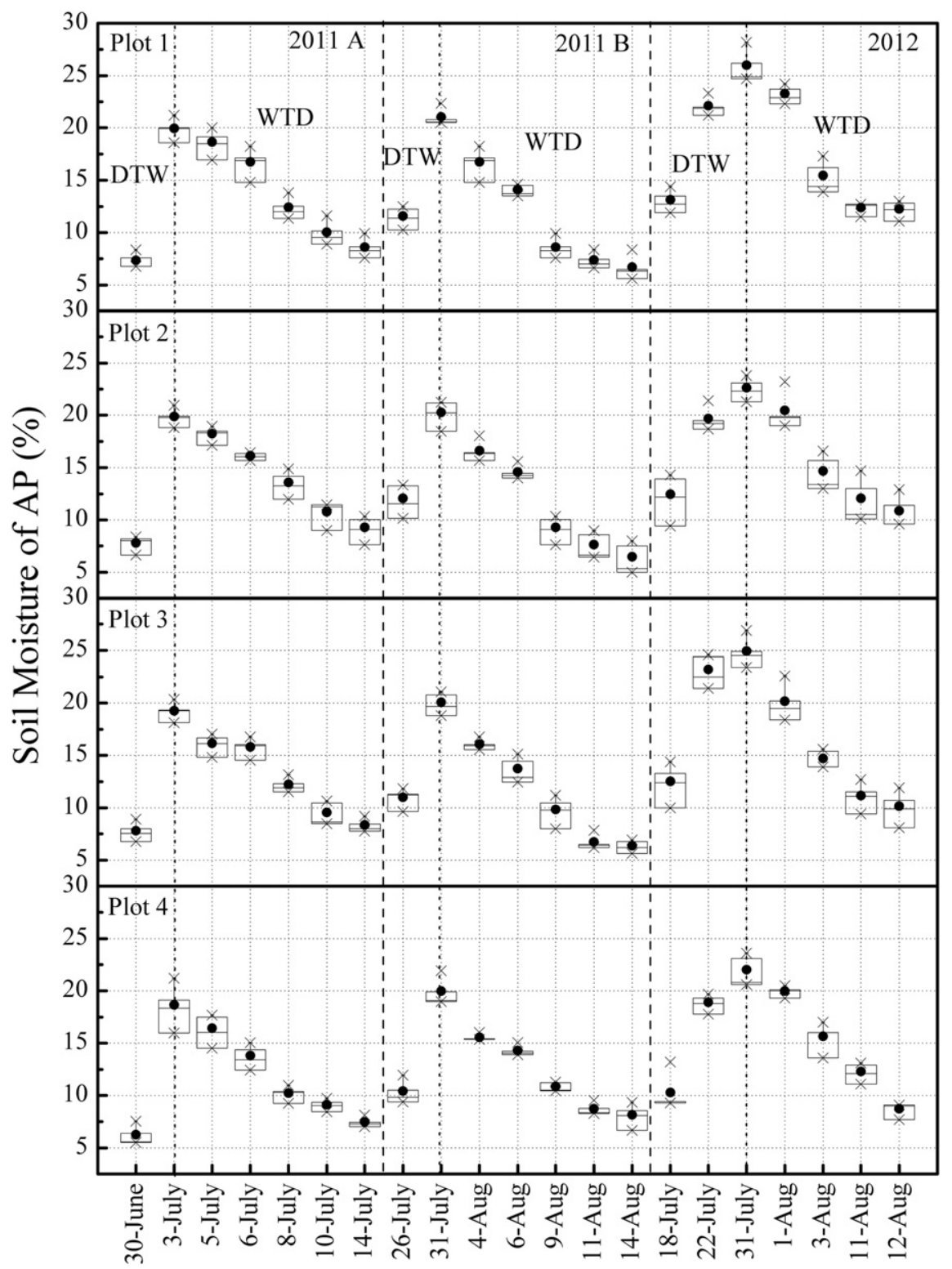

Fig. 4. The distribution of soil moisture in AP areas of different types of microplot over three soil moisture responses. 
where $\theta_{C P(i, j)}$ is the soil moisture of the $\mathrm{CP}$ area on the $i$ th microplot ( $i=1-16)$ at $j$ th observation time $(j=1-2$, indicates the DTW process; $j=3-7$, indicates WTD process), and $\bar{\theta}_{C P(* \cdot j)}$ represents the average soil moisture in the $\mathrm{CP}$ of all of the microplots at the $j$ th time. Therefore, $\Delta_{C P(i, j)}$ and $\delta_{C P(i, j)}$ reflect the fluctuation of the soil moisture and relative difference in the $\mathrm{CP}$ at the corresponding microplot and observation time, respectively.With respect to the APs, the relative difference was calculated using Eqs. (4)-(7) as follows:

$\bar{\theta}_{A P(i, j)}=\frac{\sum_{p=1}^{4} \theta_{A P(i, j, p)}}{4}$

$\overline{\bar{\theta}}_{A P(* j)}=\frac{\sum_{i=1}^{16} \bar{\theta}_{A P(i, j)}}{16}=\frac{\sum_{i=1}^{16} \sum_{p=1}^{4} \theta_{A P(i, j, p)}}{64}$

$\Delta_{A P(i, j)}=\bar{\theta}_{A P(i, j)}-\overline{\bar{\theta}}_{A P(* j)}$
$\delta_{A P(i, j)}=\frac{\Delta_{A P(i, j)}}{\overline{\bar{\theta}}_{A P(* \cdot j)}}$

where $\bar{\theta}_{A P(i, j)}$ is the average soil moisture of the four APs that were located in different positions ( $s$ ort for $p$ ) on the $i$ th microplot at the $j$ th time. In all of the microplots, the average soil moisture in the APs at the $j$ th time is displayed as $\overline{\bar{\theta}}_{A P(* \cdot j)}$. Finally, the TSSM-MRD of the CP and $\operatorname{APs}\left(\delta_{C P(i, j)_{n}}, \bar{\delta}_{A P(i, j)_{n}}\right)$ was calculated using Eqs. (8) and (9), respectively. $n=1-2$, indicates the DTW process; $n=3 \sim 7$, indicates the WTD process-the same relationship is used below

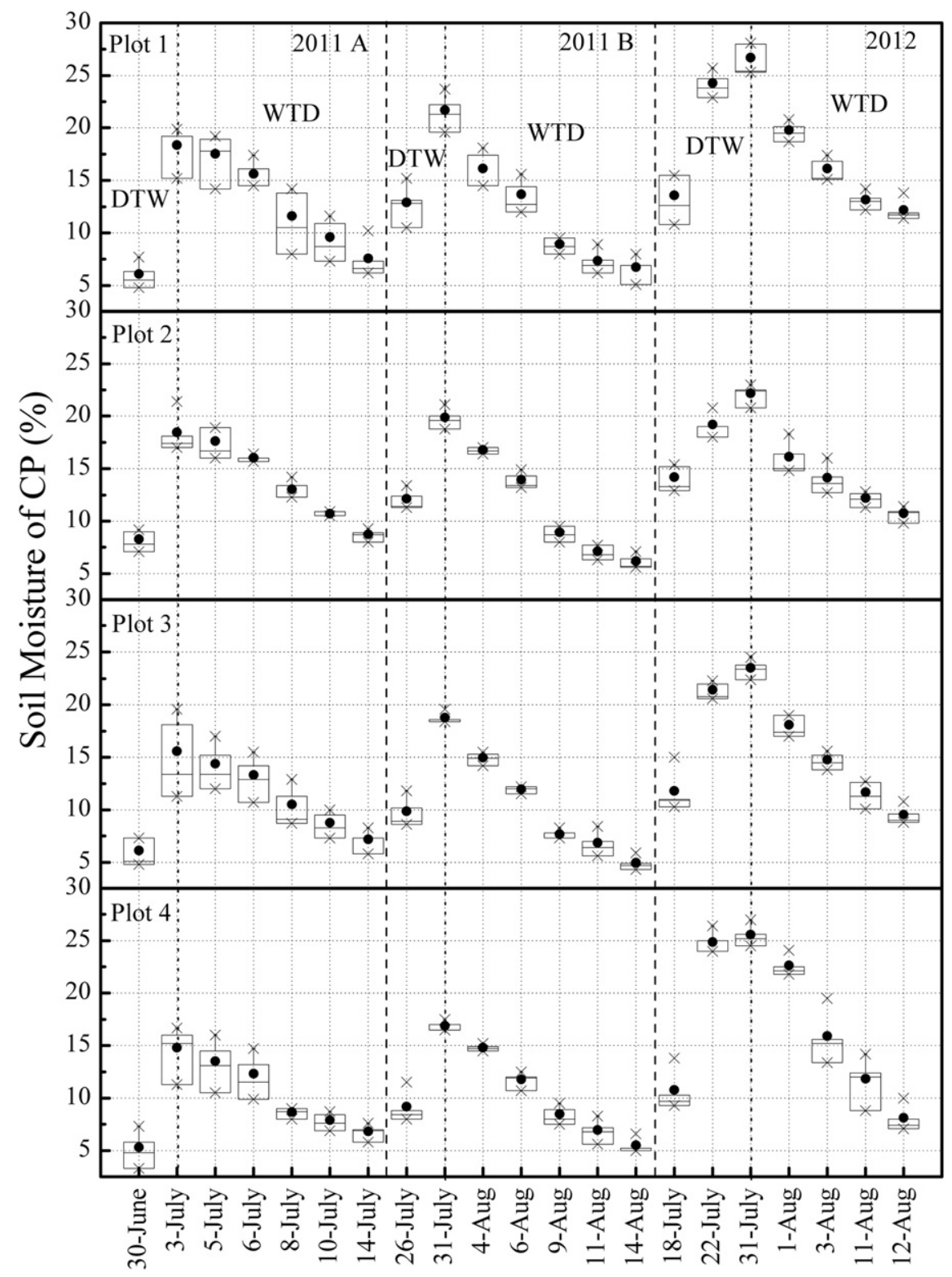

Fig. 5. The distribution of soil moisture in $\mathrm{CP}$ areas of different types of microplot over three soil moisture responses. 
$\bar{\delta}_{A P(i, j)_{n}}=\frac{\sum_{j=1}^{n} \delta_{A P(i, j)}}{n}=\frac{\sum_{j=1}^{n}\left(16 \sum_{p=1}^{4} \theta_{A P(i, j, p)}-\frac{\sum_{i=1}^{16} \sum_{p=1}^{4} \theta_{A P(i, j, p)}}{\sum_{i=1}^{16} \sum_{p=1}^{4} \theta_{A P(i, j, p)}}\right)}{n}$.

Furthermore, if we synthesized the TSSM-MRD of the CP and APs, and obtained the TSSM-MRD of the specific microplot from Eqs. (10) to (14), which represents a similar meaning as the above equations, then

$\theta_{M(i \cdot j)}=\frac{\theta_{C P(i, j)}+\sum_{p=1}^{4} \theta_{A P(i, j, p)}}{5}$

$\bar{\theta}_{M(* \cdot j)}=\frac{\sum_{i=1}^{16} \theta_{M(i, j)}}{16}$

$\Delta_{M(i, j)}=\theta_{M(i, j)}-\bar{\theta}_{M(* \cdot j)}$

$\delta_{M(i, j)}=\frac{\Delta_{M(i, j)}}{\bar{\theta}_{M(* \cdot j)}}$

$\bar{\delta}_{M(i, j)_{n}}=\frac{\sum_{j=1}^{n} \delta_{A P(i, j)}}{n}=\frac{\sum_{j=1}^{n}\left(\frac{16_{M(i, j)}-\sum_{i=1}^{16} \theta_{M(i, j)}}{\sum_{i=1}^{16} \theta_{M(i, j)}}\right)}{n}$

where the TSSM-MRD indicates the fluctuation of every measuring points (Vachaud et al., 1985) compared with the average soil water content value throughout the DTW or WTD processes in the CP or APs' sampling areas. Specifically, the more closely the absolute value of TSSM-MRD approaches zero, the more likely the corresponding soil moisture represents the mean-soil-moisture in the entire spatial patterns that are formed by the $\mathrm{CP}$ or APs' distribution throughout the corresponding hydrological processes. Moreover, the value of TSSMMRD indicates that whether the value of the soil moisture measurement point overestimates $\left(\bar{\delta}_{C P(i, j)_{m}}>0 ; \bar{\delta}_{A P(i, j)_{m}}>0\right)$ or underestimates $\left(\bar{\delta}_{C P(i, j)_{m}}<\right.$ $0 ; \bar{\delta}_{A P(i, j)_{m}}<0$ ) (Vachaud et al., 1985) the average value throughout the DTW or WTD period. Based on Eqs. (8), (9), and (14), the standard deviation of the MRD of TSSM (TSSM-STD) in the CP, APs and microplot $\left(\varsigma\left(\bar{\delta}_{C P(i, j)_{n}}\right), \varsigma\left(\bar{\delta}_{A P(i, j)_{n}}\right)\right.$ and $\left.\varsigma\left(\bar{\delta}_{M(i, j)_{n}}\right)\right)$ could be calculated respectively, using $\mathrm{CP}$ for example.

$\varsigma\left(\bar{\delta}_{C P(i \cdot j)_{n}}\right)=\sqrt{\sum_{j=1}^{n} \frac{\left(\delta_{C P(i, j)}-\bar{\delta}_{C P(i \cdot j)_{n}}\right)^{2}}{n} .}$

The TSSM-STD reflects the fluctuation of the TSSM-MRD (Starks et al., 2006) in a specific type of soil moisture measuring point. If the absolute value of the TSSM-STD in a given microplot or CP or APs approaches zero more closely, then this value is considered to be better representing the lower fluctuant of TSSM-MRD, and higher stability process over which the corresponding soil moisture gradually approached the entire-spatial-pattern average soil moisture. Additionally, the index of temporal stability (TSSM-ITS) in the CP, AP and microplots ( ITS $_{\mathrm{CPn}_{n}}$, ITS $\mathrm{APn}_{\mathrm{APn}}$ and ITS $\mathrm{Mn}_{\mathrm{n}}$ ) combines the TSSM-MRD and

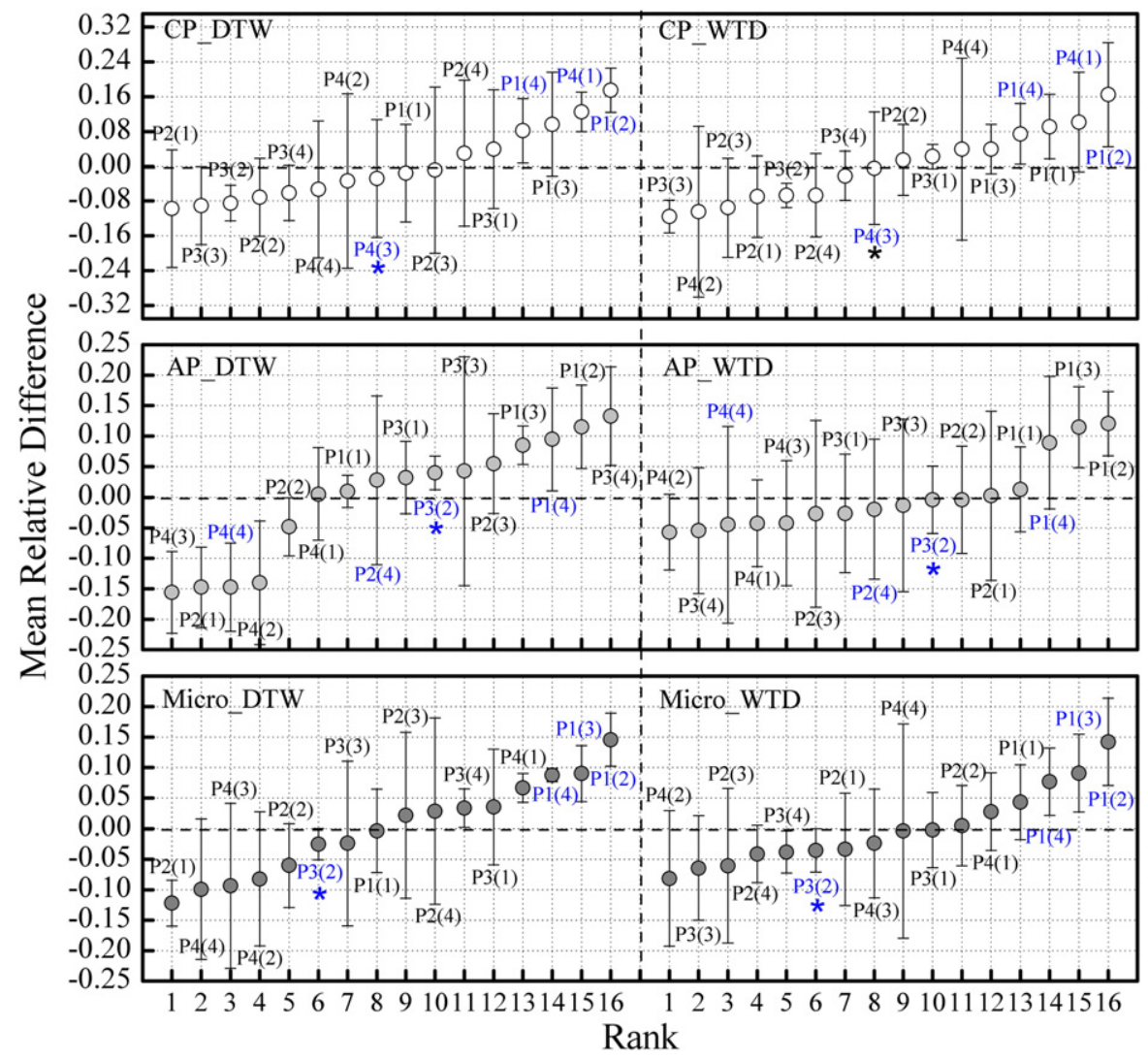

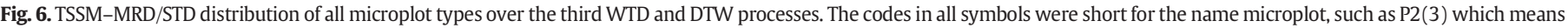

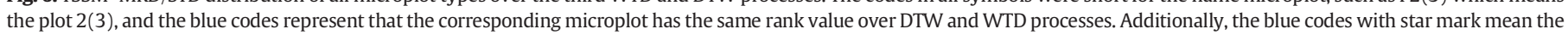
corresponding same-rank-value microplots that have the lowest absolute value of TSSM-MRD over the DTW and WTD processes. 
TSSM-STD (Jacobs et al., 2004; Penna et al., 2013; Zhao et al., 2010) and uses $\mathrm{CP}$ as an example:

$I T S_{C P_{n}}=\sqrt{\left(\bar{\delta}_{C P(i, j)_{n}}\right)^{2}+\left(\delta\left(\bar{\delta}_{C P(i \cdot j)_{n}}\right)\right)^{2}}$.

The lower value of ITS in the CP or AP or some microplots indicates the higher TSSM of the corresponding soil moisture measuring point or location or vice versa.

\subsubsection{The calculation of the TSSM by a probability function}

The cumulative probability distribution in the TSSM (Vachaud et al., 1985) (TSSM-CumP) calculation in the CP can be used as an example in Eq. (17) as follows:

$\bar{\theta}_{C P(i \cdot *)}=\frac{\sum_{j=1}^{n} \theta_{C P(i, j)}}{n}$

where $\bar{\theta}_{C P(i *)}$ is the average soil moisture of the $i$ th microplot $(i=1-16)$ at CP location throughout DTW or WTD processes $(j=n=1-2$, indicates the DTW process; $j=n=3-7$, indicates the WTD process). The different values of $\bar{\theta}_{C P(i * *)}$ were ranked from lowest to highest, such as $\bar{\theta}_{C P[i * *]}<\bar{\theta}_{C P[2 * *]}<\ldots<\bar{\theta}_{C P[16 * *]}$, in which the number in the square bracket indicates the order of the average soil moisture. Additionally, the average soil moisture in the $\mathrm{CP}$ areas of all of the microplots over $n$ times is expressed by Eq. (18):

$\theta_{C P(* * *)}=\sum_{i=1}^{16} \bar{\theta}_{C P(i \cdot *)}=\frac{\sum_{j=1}^{n} \sum_{i=1}^{16} \theta_{C P(i, j)}}{n}$.

Therefore, the probability of the lowest average soil moisture in the $\mathrm{CP}$ point of some microplots over $n$ observational times $p\left(\bar{\theta}_{C P[1 * *]}\right)$ could be calculated by Eq. (19):

$p\left(\bar{\theta}_{C P[1 *]}\right)=\bar{\theta}_{C P[1 *]} / \theta_{C P[* * *]} ; \quad p\left(\bar{\theta}_{C P[1 * *]}\right) \in(0,1]$.

Based on this equation, the TSSM-CumuP of the $k$ th highest soil moisture in CP point of some microplot, $\operatorname{CumuP}\left(\bar{\theta}_{C P[k \cdot *]}\right)$ could be expressed by Eq. (20):

$$
\begin{aligned}
\operatorname{Cumu}\left(\bar{\theta}_{C P[k * *]}\right) & =p\left(\bar{\theta}_{C P[1 * *]}\right)+p\left(\bar{\theta}_{C P[2 * *]}\right)+\ldots+p\left(\bar{\theta}_{C P[k * *]}\right) \\
& =\sum_{k=1}^{k} p\left(\bar{\theta}_{C P[k * *]}\right) .
\end{aligned}
$$

The TSSM-CumP reflects the rank stability of the soil moisture based on the probability density function conforming to a normal distribution. Moreover, if the TSSM-CumP of the soil moisture in the CP or AP points or a specific microplot has the same cumulative probability distribution

Table 3

\begin{tabular}{|c|c|c|c|c|c|c|c|c|c|c|c|}
\hline \multirow[t]{2}{*}{ Position/scale } & \multirow[t]{2}{*}{ Code } & \multicolumn{5}{|c|}{ DTW processes } & \multicolumn{5}{|l|}{ WTD processes } \\
\hline & & TSSM-CumP & $\begin{array}{l}\text { TSSM-MRD } \\
\text { OEM }\end{array}$ & $\begin{array}{l}\text { TSSM-MRD } \\
\text { UEM }\end{array}$ & $\begin{array}{l}\text { Average } \\
\text { TSSM-STD }\end{array}$ & $\begin{array}{l}\text { Average } \\
\text { TSSM-ITS }\end{array}$ & TSSM-CumP & $\begin{array}{l}\text { TSSM-MRD } \\
\text { OEM }\end{array}$ & $\begin{array}{l}\text { TSSM-MRD } \\
\text { UEM }\end{array}$ & $\begin{array}{l}\text { Average } \\
\text { TSSM-STD }\end{array}$ & $\begin{array}{l}\text { Average } \\
\text { TSSM-ITS }\end{array}$ \\
\hline \multirow[t]{4}{*}{ 1st_CPa } & Plot 1 & $(1) / 0.49^{b}$ & $(2)(3)^{c}$ & $(1)(4)^{d}$ & 0.110 & 0.183 & $(1) / 0.50$ & $(2)(3)$ & $(1)(4)$ & 0.107 & 0.190 \\
\hline & Plot 2 & $(1) / 0.56$ & $(1)(2)(3)(4)$ & $\times$ & 0.131 & 0.240 & (3)/0.56 & $(1)(2)(3)(4)$ & $\times$ & 0.055 & 0.158 \\
\hline & Plot 3 & $\times$ & $(2)(3)$ & $(1)(4)$ & 0.046 & 0.194 & $x^{e}$ & (4) & $(1)(2)(3)$ & 0.055 & 0.129 \\
\hline & Plot 4 & $x$ & (2) & $(1)(3)(4)$ & 0.090 & 0.212 & $\times$ & $x$ & $(1)(2)(3)(4)$ & 0.072 & 0.171 \\
\hline \multirow[t]{4}{*}{ 1st_AP } & Plot 1 & $(4) / 0.53$ & $(2)(4)$ & $(1)(3)$ & 0.036 & 0.074 & $\times$ & $(1)(2)(3)$ & (4) & 0.037 & 0.091 \\
\hline & Plot 2 & $\times$ & $(2)(3)(4)$ & (1) & 0.053 & 0.096 & $\times$ & $(2)(3)(4)$ & (1) & 0.066 & 0.118 \\
\hline & Plot 3 & $(2) / 0.58$ & $(1)(2)(3)$ & (4) & 0.084 & 0.103 & (2)/0.57 (4)/0.52 & (1) & $(2)(3)(4)$ & 0.048 & 0.074 \\
\hline & Plot 4 & $\times$ & (1) & $(2)(3)(4)$ & 0.073 & 0.148 & $\times$ & $\times$ & $(1)(2)(3)(4)$ & 0.057 & 0.121 \\
\hline \multirow[t]{4}{*}{ 1st_M } & Plot 1 & (1)/0.52 & $(2)(3)$ & (1)(4) & 0.057 & 0.093 & (4)/0.51 & $(2)(3)$ & (1)(4) & 0.064 & 0.124 \\
\hline & Plot 2 & $\times$ & $(1)(2)(3)(4)$ & $\times$ & 0.079 & 0.141 & $\times$ & $(1)(2)(3)(4)$ & $x$ & 0.051 & 0.124 \\
\hline & Plot 3 & $(2) / 0.58$ & $(2)(3)$ & $(1)(4)$ & 0.058 & 0.122 & $(2) / 0.57$ & (4) & $(1)(2)(3)$ & 0.038 & 0.080 \\
\hline & Plot 4 & $\times$ & $\times$ & $(1)(2)(3)(4)$ & 0.061 & 0.138 & $\times$ & $\times$ & $(1)(2)(3)(4)$ & 0.043 & 0.136 \\
\hline \multirow[t]{4}{*}{ 2nd_CP } & Plot 1 & $\times$ & $(1)(2)(3)$ & (4) & 0.078 & 0.179 & $(4) / 0.53$ & $(2)(3)(4)$ & (1) & 0.126 & 0.159 \\
\hline & Plot 2 & (4)/0.51 & $(1)(2)(3)(4)$ & $\times$ & 0.050 & 0.086 & $\times$ & $(1)(2)(3)(4)$ & $\times$ & 0.070 & 0.098 \\
\hline & Plot 3 & $(4) / 0.57$ & (1) & $(2)(3)(4)$ & 0.093 & 0.124 & $(4) / 0.59$ & $\times$ & $(1)(2)(3)(4)$ & 0.082 & 0.122 \\
\hline & Plot 4 & $\times$ & $\times$ & $(1)(2)(3)(4)$ & 0.078 & 0.176 & $\times$ & (3) & $(1)(2)(4)$ & 0.068 & 0.106 \\
\hline \multirow[t]{4}{*}{ 2nd_AP } & Plot 1 & $\times$ & $(2)(4)$ & (1)(4) & 0.034 & 0.068 & $(4) / 0.49$ & $(2)(4)$ & (1)(3) & 0.103 & 0.122 \\
\hline & Plot 2 & $(2) / 0.59$ & $(2)(3)(4)$ & (1) & 0.060 & 0.109 & $\times$ & (3)(4) & $(1)(2)$ & 0.095 & 0.135 \\
\hline & Plot 3 & $(2) / 0.53$ & $(2)(4)$ & $(1)(3)$ & 0.040 & 0.062 & $(2) / 0.54$ & $\times$ & $(1)(2)(3)(4)$ & 0.097 & 0.112 \\
\hline & Plot 4 & $\times$ & (1) & $(2)(3)(4)$ & 0.040 & 0.096 & $\times$ & $(1)$ & $(2)(3)(4)$ & 0.112 & 0.142 \\
\hline \multirow[t]{4}{*}{ 2nd_M } & Plot 1 & $\times$ & $(1)(2)(3)(4)$ & $\times$ & 0.053 & 0.103 & $\times$ & $(2)(3)(4)$ & (1) & 0.101 & 0.120 \\
\hline & Plot 2 & $(2) / 0.59$ & $(2)(3)(4)$ & $(1)$ & 0.053 & 0.079 & (1)/0.48 & $(3)(4)$ & $(1)(2)$ & 0.069 & 0.095 \\
\hline & Plot 3 & $(2) / 0.53$ & (2) & $(1)(3)(4)$ & 0.052 & 0.081 & $(2) / 0.53$ & $\times$ & $(1)(2)(3)(4)$ & 0.074 & 0.099 \\
\hline & Plot 4 & $\times$ & (1) & $(2)(3)(4)$ & 0.056 & 0.125 & $\times$ & $(4)$ & $(1)(2)(3)$ & 0.071 & 0.089 \\
\hline \multirow[t]{4}{*}{ 3rd_CP } & Plot 1 & $\times$ & $(2)(3)(4)$ & (1) & 0.09 & 0.139 & $\times$ & $(1)(2)(3)(4)$ & $\times$ & 0.08 & 0.123 \\
\hline & Plot 2 & $(4) / 0.47$ & (4) & $(1)(2)(3)$ & 0.15 & 0.160 & $(2) / 0.47$ & (2) & $(1)(3)(4)$ & 0.09 & 0.116 \\
\hline & Plot 3 & $\times$ & (1) & $(2)(3)(4)$ & 0.08 & 0.113 & (1)/0.53 & (1) & $(2)(3)(4)$ & 0.04 & 0.073 \\
\hline & Plot 4 & $(2) / 0.53$ & (1) & $(2)(3)(4)$ & 0.13 & 0.160 & $\times$ & $(1)(4)$ & $(2)(3)$ & 0.16 & 0.179 \\
\hline \multirow[t]{4}{*}{ 3rd_AP } & Plot 1 & (1)/0.46 & $(1)(2)(3)(4)$ & $\times$ & 0.05 & 0.095 & $\times$ & $(1)(2)(3)(4)$ & $\times$ & 0.07 & 0.119 \\
\hline & Plot 2 & $\times$ & (1)(2) & $(3)(4)$ & 0.08 & 0.117 & $(1) / 0.48(4) / 0.54$ & (1) & $(2)(3)(4)$ & 0.12 & 0.125 \\
\hline & Plot 3 & (1)/0.53 & $(1)(2)(3)(4)$ & $\times$ & 0.09 & 0.116 & $\times$ & $\times$ & $(1)(2)(3)(4)$ & 0.10 & 0.104 \\
\hline & Plot 4 & $\times$ & (1) & $(2)(3)(4)$ & 0.08 & 0.146 & $\times$ & $\times$ & $(1)(2)(3)(4)$ & 0.10 & 0.112 \\
\hline \multirow[t]{4}{*}{ 3rd_M } & Plot 1 & $\times$ & $(2)(3)(4)$ & (1) & 0.04 & 0.103 & $\times$ & $(1)(2)(3)(4)$ & & 0.06 & 0.110 \\
\hline & Plot 2 & $(4) / 0.47$ & $(3)(4)$ & (1)(2) & 0.10 & 0.128 & $\times$ & (2) & $(1)(3)(4)$ & 0.08 & 0.092 \\
\hline & Plot 3 & (3)/0.54 & (1)(4) & $(2)(3)$ & 0.07 & 0.080 & $(1) / 0.54$ & $x$ & $(1)(2)(3)(4)$ & 0.05 & 0.068 \\
\hline & Plot 4 & $\times$ & (1) & $(2)(3)(4)$ & 0.09 & 0.131 & (3)/0.31 & (1) & $(2)(3)(4)$ & 0.11 & 0.119 \\
\hline
\end{tabular}

The characteristics of indices in TSSM analysis system over three DTW and WTD processes.

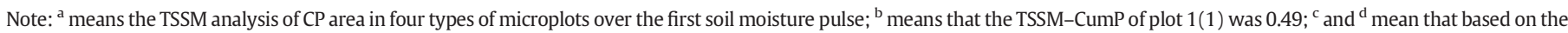

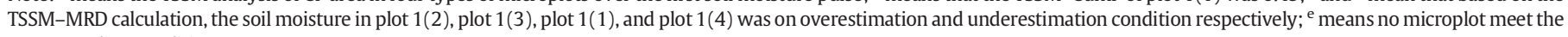
corresponding condition. 
in both the WTD and DTW processes, but the corresponding TSSMCumP value is approximately 0.50 , then the corresponding soil moisture in the CP or AP areas or a specific microplot could be characterized by the spatial mean soil moisture content.

\section{Results}

\subsection{The temporal pattern of the soil moisture-response}

Fig. 2 indicates the long time average soil moisture dynamics of the four microplot types which were influenced by the 10 obvious rainfall events (precipitation $>5 \mathrm{~mm}$ ) and a total of 22 high temperature events (average temperature $>30$ centigrade) during the rainy season of 2011 and 2012. There exists three typical soil moisture dynamics processes distributing throughout 2011A (June 30th, to July 14th, 2011), 2011B (from July 26 to August 15th, 2011), and 2012 (from July 18th to August 12th, 2012) respectively, which were indicated in different vegetation types and bare land on microplot (Fig. 3), AP (Fig. 4) and CP (Fig. 5) scales. Affected by the precipitation in 2012, the soil water content in the same vegetation types or bare land seemed to be higher than that of 2011A and 2011B throughout both the DTW and WTD processes. Under the same precipitation and radiation conditions, in the $\mathrm{CP}$ area, the fluctuations of the soil moisture in the vegetation types such as plot 3 and plot 4 ranged from $6.4 \%$ to $24.9 \%$ as well as from $6.3 \%$ to $22.0 \%$ respectively, which were more obvious than the corresponding types in the AP area at every observational interval. This diversity was more distinct between the $\mathrm{CP}$ and AP areas when the soil moisture changed from WTD to DTW. Meanwhile, in the same temporal pattern of soil moisture, compared to the vegetation types, the soil moisture response fluctuation of the bare land (plot 1 ) at $\mathrm{CP}$ (ranging from $6.1 \%$ to $26.7 \%$ ), AP (ranging from $6.7 \%$ to $26.0 \%$ ) and microplot (ranging from $6.7 \%$ to $26.4 \%$ ) scales seemed to be more obvious than the corresponding positions in all of the observational intervals. Moreover, throughout the same DTW process, the average soil moisture in the bare land was larger than that of the vegetation types at the corresponding CP, AP and microplot scales. During the same WTD process, in the $\mathrm{CP}$, the soil moisture in the vegetation microplots (plot 3 and plot 4) which averagely reduced $12.1 \%$ and $11.5 \%$ respectively seemed to be decreased more obviously than that of the bare land in the corresponding area. This phenomenon was more evident when the observational intervals were from August 3rd to August 12th in 2012 during the WTD processes of the third soil moisture response.

\subsection{TSSM-MRD/STD/ITS characteristics of different vegetation types}

According to the TSSM analysis calculation system, we used the third soil moisture responses as example to analyze TSSM characteristics. In Fig. 6, the TSSM-MRD and TSSM-STD distribution of all of the vegetation types and bare land under DTW and WTD processes at CP, AP and microplot scales is indicated. With respect to $\mathrm{CP}$ area, the rank value of plot 4(3) and plot 4(1) is 8 and 15 respectively, both of which have the same rank value over DTW and DTW processes. And other two bare microplots plot 1(4) and plot 1(2) whose rank values are 13 and 16 respectively also have the same rank values. Regarding the AP area, a grass microplot (plot 2(4)), a low shrub microplot (plot 3(2)), a tall shrub microplot (plot 4(4)) and a bare microplot (plot 1(4)) whose rank values were $8,10,3$ and 14 respectively, have the same rank values throughout the third DTW and WTD processes. Moreover, as to the microplot scale, plot 1(2), plot 1(3) and plot 1(4) have the same rank value which were 16, 15 and 6 respectively, In addition, the samerank-value microplot whose absolute values of TSSM-MRD approaching zero indicated stronger TSSM and, better representativeness of the average soil moisture given the corresponding temporal pattern. Therefore, from the view of statistical characteristics of the TSSM, the

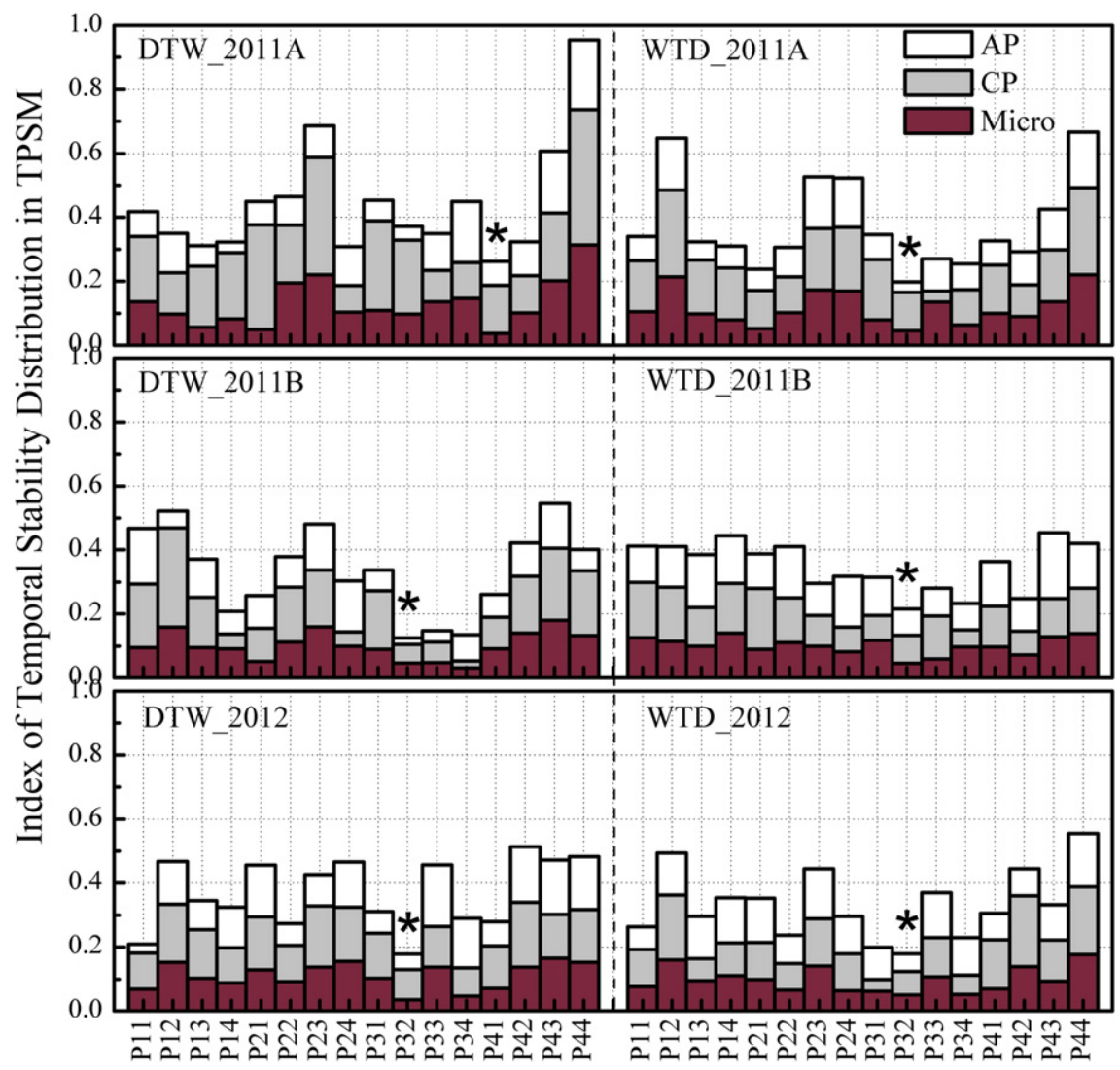

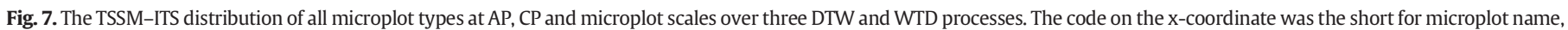
such as P11 which means the plot 1(1). And the star mark indicates the lowest sum of TSSM-ITS at AP, CP and microplot scales over DTW or WTD process. 


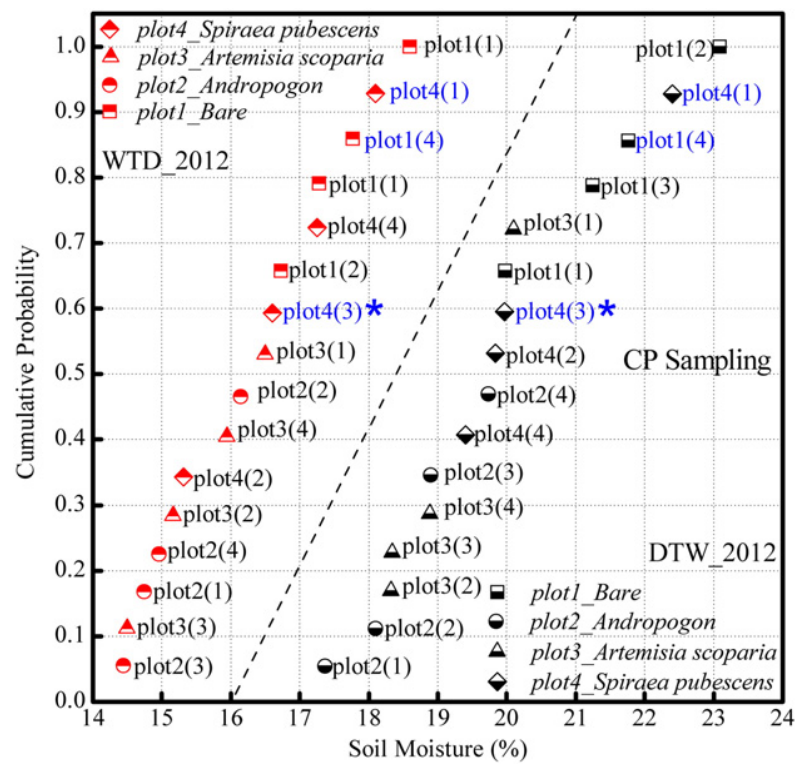

Fig. 8. The TSSM-CumP distribution of CP in DTW and WTD processes of 2012 rainy season, the red symbols on the left side indicates the distribution of cumulative probability of soil moisture in $\mathrm{CP}$ of different microplots over WTD processes, and the black marks on the right side displayed the distribution of CP in different microplots over DTW processes. Additionally, the blue codes represent the corresponding microplot that has the same TSSM-CumP value over DTW and WTD processes, the blue codes with star mark means the TSSM-CumP values in corresponding microplots relative closed to 0.5 .

soil moisture in plot 3(2) indicated a higher temporal persistence at the $\mathrm{AP}$ and microplot scales during the third soil moisture response process, and the soil water content in plot 4(3) represented stronger temporal stability in the $\mathrm{CP}$ areas throughout the DTW and WTD processes. And in the three soil moisture responses during the rainy seasons, the TSSM-MRD and TSSM-STD characteristics at the CP, AP and microplot scales are presented in Table 3. Additionally, the TSSM-ITS characteristics of all of the vegetation types and bare land at the CP, AP and microplot scales throughout three different soil moisture responses are shown in Fig. 7. For the first soil moisture response (2011A), throughout the DTW process, the sum the of TSSM-ITS at the CP, AP and microplot scales equaling 0.26 in plot $4(1)$ was the lowest in the 16 microplots, however, the lowest corresponding sum of the TSSMITS in all of the microplots appeared in plot 3(2) equaling 0.19 throughout the WTD process. Regarding the other two soil moisture responses in 2011B and 2012, the sum of the TSSM-ITS in plot 3(2) equaling 0.12 and 0.22 respectively in the DTW and WTD processes, and the lowest TSSM-ITS indicated that the soil moisture in plot 3(2) had more obvious temporal persistence throughout the hydrological processes. Finally, in Table 3, the TSSM analysis system including TSSM-MRD, TSSM-STD, TSSM-ITS in DTW and WTD processes indicates the difference of TSSM characteristics in the four microplot types.

\subsection{TSSM-CumP characteristics of different vegetation types}

The TSSM-CumP that was calculated by Eq. (20) was characterized as the probability-trait index to evaluate the TSSM features. The TSSM-CumP characteristics at the CP over DTW and WTD processes in 2012 are shown in Fig. 8. And values of TSSM-CumP of all vegetation types under $\mathrm{CP}$, AP and microplot scales, and the determined microplots whose TSSM-CumP value approaches to 0.5 were also shown in Table 3 . In the CP area, throughout the WTD and DTW processes, two high shrub microplot (plot 4(1) and plot 4(3)) and plot 1(4) had the same cumulative probability distribution respectively. In the three microplots, the TSSM-CumP of plot $4(3)$ equaling 0.60 , was more likely to be

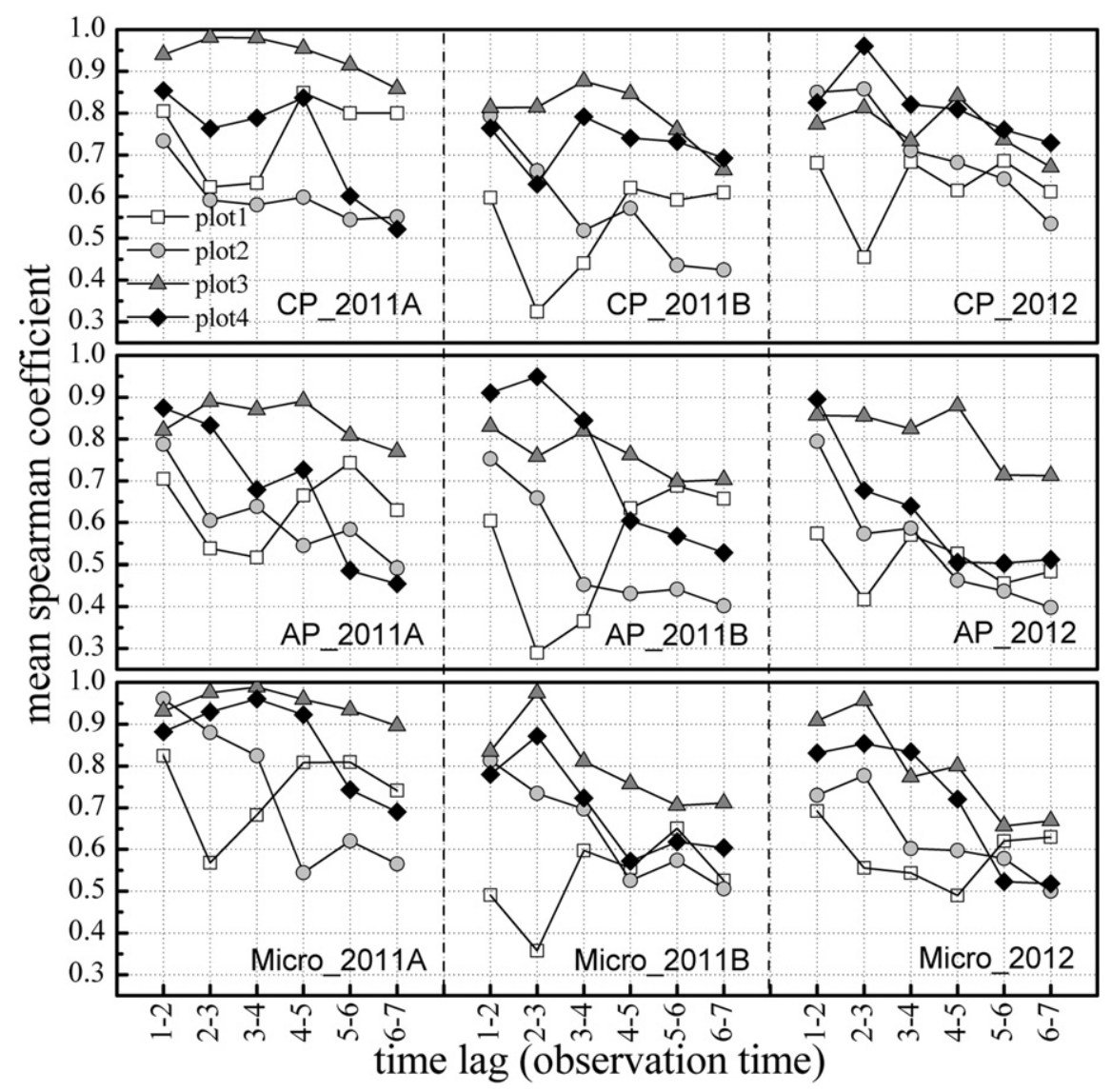

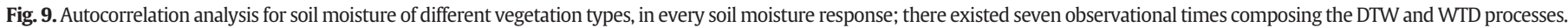


approximately 0.50 . Therefore, regarding the probabilistic characteristics of the TSSM, the soil moisture in plot 4(3) indicated a greater TSSM and most likely represented the average soil moisture of all of all $\mathrm{CP}$ areas that were distributed on the hillslope throughout the third soil moisture pulses process. Moreover, in Table 3, regarding to the AP scales, there were more microplots with the same cumulative probability distribution throughout the two hydrological processes, although, the soil water content in plot 3(2) seemed to be more representative of higher temporal stability characteristics. At the microplot scale, compared with the other three bare lands (plot 1(2), plot 1(3) and plot 1(4)) which had the same cumulative probability distribution throughout the DTW and WTD processes, the TSSM-CumP of the low shrub microplot (plot 3(2)) seems more close to 0.5 .

\section{Discussion}

\subsection{Time series analysis (TSA) of the temporal pattern of soil moisture}

TSA is widely used to evaluate the temporal pattern of soil moisture, (Brocca et al., 2009; Heathman et al., 2012; Martinez-Fernandez and Ceballos, 2003; Vachaud et al., 1985) and a higher autocorrelation coefficient indicates a lower temporal fluctuation of soil moisture. In this research, the autocorrelation coefficient evaluation describes the temporal dynamic characteristics of soil moisture throughout the entire hydrological responses. A hydrological response consists of both DTW and WTD processes which were affected by the precipitation and radiation respectively. The distribution of the autocorrelation coefficient at the $\mathrm{CP}, \mathrm{AP}$ and microplot scales throughout three soil moisture responses of different vegetation types is shown in Fig. 9. The autocorrelation coefficient of all vegetation types in the CP and AP areas decreased with the increasing observational duration, especially during the WTD process (the time lag from 2-3 to 6-7 in Fig. 9). TSA in CP, AP and microplot scales indicates that the consumption of water in the soil layer by evapotranspiration increased the fluctuation of the soil moisture throughout the WTD processes. The characteristics of temporal of soil moisture pattern are, to some extent, similar to those of GomezPlaza et al. (2000) who also reported that the heterogeneity of a plant could decrease the TSSM. However, there are also some differences in our study from the conclusion of Gomez-Plaza et al. (2000). Specifically, in the AP area, the autocorrelation coefficient, especially at the end of the WTD process (time lag from 5-6 to 6-7), stopped decreasing and even tended to increase, probably related to litter layer playing the act on restricting surface soil water from transpiring (Hartanto et al., 2003). Therefore, in the complex root-soil interface environment of soil water movement that is created by the root system extending in the soil layer of vegetation types (Caldwell et al., 1998; Dawson, 1993; Eagleson, 1978b,1978c; Horton and Hart, 1998; Porporato et al., 2001, 2002; Rodriguez-Iturbe et al., 2001), the dynamic balance of water resources-such as water conservation caused by the litter layer and water consumption affected by the root system distribution in plot 3 and plot 4-could probably stabilize the temporal fluctuation of soil moisture. Furthermore, with respect to the former TSSM study related to the vegetation types, based on the TSA, Penna et al. (2013) indicated that, in the two contrasting morphology hillslopes, the characteristic of the TSSM was mainly related to the topographic properties. However, due to the homogeneous vegetation distribution on the hillslopes, these researchers neglected the influence of vegetation on the temporal pattern of soil moisture. Other researchers (Brocca et al., 2009; Jia and Shao, 2013; Mohanty and Skaggs, 2001) also considered the impact of vegetation on the TSSM, although the combination of TSSM characteristics with hydrological response that are impacted by vegetation seemed have not been sufficiently considered. Similar to the explanation of Zhao et al. (2010), the root structure distribution in the soil layer and the substances covering the soil surface caused to plant have a highly

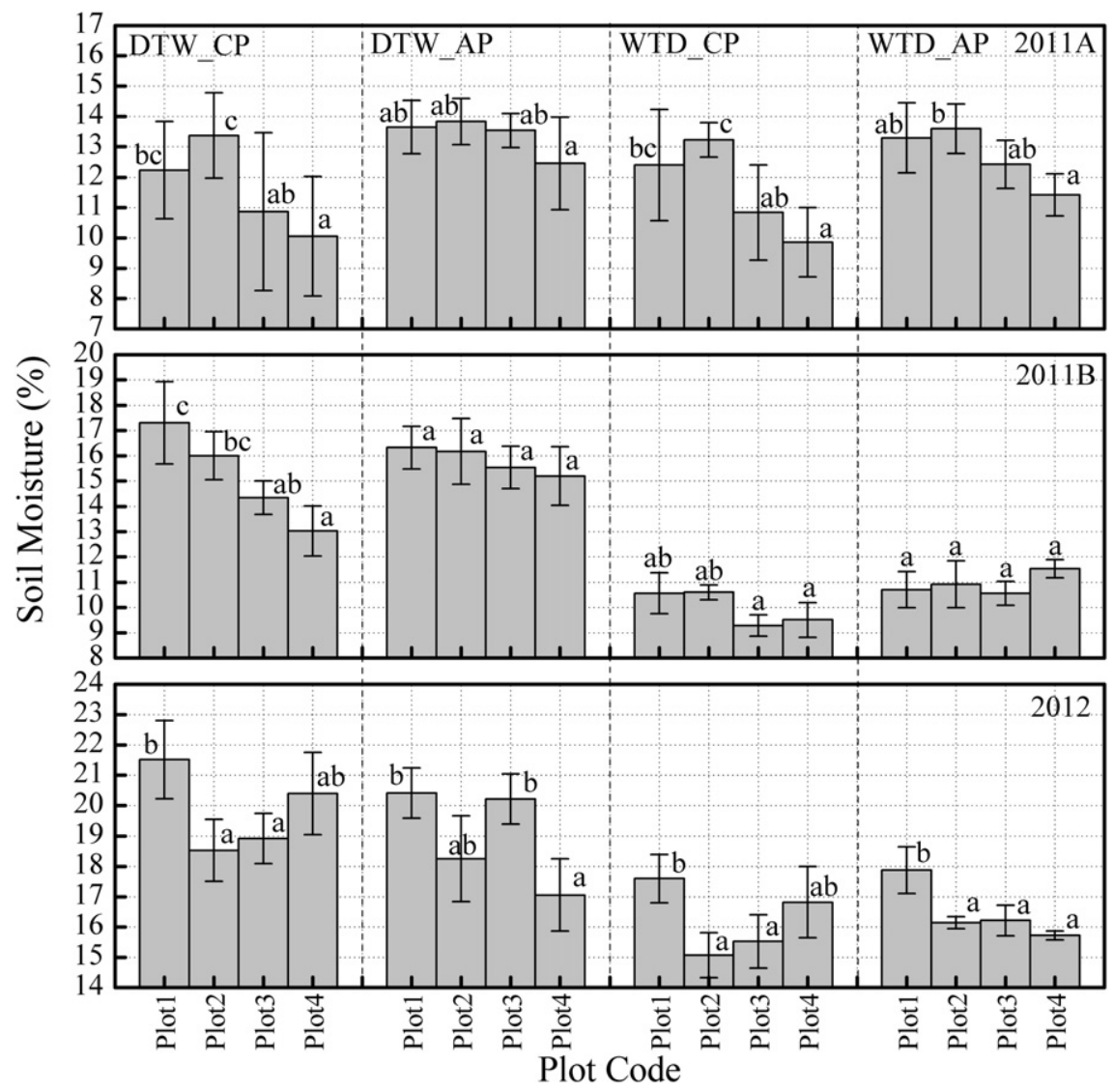

Fig. 10. Least-significant difference (LSD) analysis of soil moisture in different microplot types on CP and AP area, the same letter means no significant difference at the 0.05 level. 
dynamic water demand, which ultimately complicates the characteristics of the TSSM. Therefore, these authors suggested that it is necessary to detail information of vegetation dynamics, which could be beneficial to correlating the corresponding soil water content and to the TSSM study. In our study, the analysis of the TSSM characteristics of the $\mathrm{CP} / \mathrm{APs}$ area in vegetation types could be regarded as the response to their suggestion. In fact, three response components-the canopy being on the ground, the litter layer covering the soil surface, and the root system dispersing in the subsurface-played different roles in the hydrological response to both the DTW and WTD processes, which finally formed the tradeoff between the water evapotranspiration and conservation processes (Zhao et al., 2010), and affected the TSSM characteristics of the CP and AP in vegetation types. Moreover, Fig. 9 also shows that, throughout the DTW process (the time lag from 1-2 to $2-3$ ), compared with the vegetation types (plot 3 and plot 4), the temporal persistence of the soil water content in the bare land (plot 1) and grass land (plot 2) seemed to be less at the AP, CP and microplot scales, indicating that the direct disturbance of erosive rainfall on the soil moisture pattern could decrease the corresponding TSSM. Specifically, due to the lack of litter a layer and root structure to effectively resist the soil erosion (Gyssels et al., 2005) in plot 1 and plot 2, a greater probability of soil erosion could be generated, thereby increasing the temporal fluctuation of the corresponding soil moisture throughout the precipitation process. However, these complex soil water movement processes on the soil surface, the root-soil interface and the subsurface could make it difficult to determine the specific response units of the soil water dynamics and to interpret all of the TSSM characteristics in the AP and $\mathrm{CP}$ areas of the vegetated and bare microplots.

\subsection{Influential analysis of vegetation types on soil moisture response in the $C P / A P S$}

Similar soil moisture response existed in different vegetation types and bare land, although, regarding the different microplot types, throughout the same DTW and WTD process, the soil moisture response in the same sampling area (CP or AP) indicates significant differences, shown in Fig. 10. These differences indicate that the diversity of the vegetation morphological characteristics lead to the more complicated hydrological response recycling in the soil-plant-atmosphere continuum (Li, 2011), and impacts the TSSM characteristics of different vegetation types (Zhao et al., 2010).

First, in the $\mathrm{CP}$ area of the vegetation types, the soil moisture response is mainly affected by the porous structures being beneficial to infiltration or evaporation, the stem structures generating stemflow (Levia and Frost, 2003; Li et al., 2009), and the precipitation distribution. Specifically, throughout the DTW processes, due to the tall shrub microplots (plot

Table 4

Determination of representative points of $\mathrm{CP} / \mathrm{APs}$ and microplots over three DTW and WTD processes.

\begin{tabular}{|c|c|c|c|c|c|c|c|c|}
\hline Position & Code & $\begin{array}{l}\text { Similar value } \\
\text { TSSM-CumP }\end{array}$ & $\begin{array}{l}\text { Same rank } \\
\text { TSSM-MRD }\end{array}$ & $\begin{array}{l}\text { TSSM-CumP } \\
\text { DTW/WTD }^{\mathrm{a}}\end{array}$ & $\begin{array}{l}\text { TSSM-MRD } \\
\text { DTW/WTD }\end{array}$ & $\begin{array}{l}\text { TSSM-STD } \\
\text { DTW/WTD }\end{array}$ & $\begin{array}{l}\text { TSSM-ITS } \\
\text { DTW/WTD }\end{array}$ & $\begin{array}{l}\text { Representative } \\
\text { point }\end{array}$ \\
\hline \multirow[t]{6}{*}{ 1st_CP } & Plot 1 & (1) & (1) & $0.49 / 0.50$ & $-0.002 /-0.034$ & $0.204 / 0.156$ & $0.204 / 0.160$ & Plot 3(3) \\
\hline & Plot 2 & (2) & (2) & $0.84 / 0.85$ & 0.110/0.106 & $0.141 / 0.051$ & $0.180 / 0.112$ & \\
\hline & Plot 3 & (1) & (1) & $0.08 / 0.10$ & $-0.268 /-0.180$ & $0.084 / 0.055$ & $0.281 / 0.189$ & \\
\hline & & (3) & (3) & $0.63 / 0.63$ & $-0.098 /-0.004$ & $0.003 / 0.033$ & $0.098 / 0.033$ & \\
\hline & Plot 4 & (3) & (3) & $0.24 / 0.26$ & $-0.152 /-0.139$ & $0.146 / 0.084$ & $0.211 / 0.162$ & \\
\hline & & (4) & (4) & $0.04 / 0.05$ & $-0.408 /-0.268$ & $0.113 / 0.052$ & $0.423 / 0.272$ & \\
\hline \multirow[t]{4}{*}{ 1st_AP } & Plot 1 & (2) & (2) & $0.97 / 1.00$ & $0.117 / 0.162$ & $0.037 / 0.016$ & $0.123 / 0.163$ & Plot 3(2) \\
\hline & Plot 2 & (4) & (4) & $0.11 / 0.11$ & $0.086 / 0.125$ & $0.086 / 0.090$ & $0.122 / 0.154$ & \\
\hline & Plot 3 & (2) & (2) & $0.52 / 0.53$ & $0.041 / 0.017$ & $0.010 / 0.028$ & $0.042 / 0.033$ & \\
\hline & Plot 4 & (3) & (3) & $0.05 / 0.05$ & $-0.147 /-0.109$ & $0.127 / 0.066$ & $0.194 / 0.128$ & \\
\hline \multirow[t]{4}{*}{ 1st_M } & Plot 1 & (3) & (3) & $0.71 / 0.71$ & $0.057 / 0.076$ & $0.080 / 0.063$ & $0.057 / 0.098$ & Plot 3(2) \\
\hline & Plot 2 & (3) & (3) & $1.00 / 0.92$ & $0.200 / 0.161$ & $0.905 / 0.064$ & $0.220 / 0.173$ & \\
\hline & Plot 3 & (2) & (2) & $0.58 / 0.57$ & $0.056 /-0.034$ & $0.079 / 0.029$ & $0.097 / 0.045$ & \\
\hline & Plot 4 & (4) & (4) & $0.05 / 0.05$ & $-0.304 /-0.217$ & $0.080 / 0.020$ & $0.314 / 0.220$ & \\
\hline \multirow[t]{5}{*}{ 2nd_CP } & Plot 1 & (2) & (2) & $1.00 / 1.00$ & $0.264 / 0.158$ & $0.162 / 0.063$ & $0.310 / 0.170$ & Plot 3(4) \\
\hline & Plot 2 & (3) & (3) & $0.84 / 0.86$ & $0.154 / 0.092$ & $0.087 / 0.028$ & $0.177 / 0.096$ & \\
\hline & Plot 3 & (3) & (3) & $0.34 / 0.34$ & $-0.061 /-0.031$ & $0.019 / 0.130$ & $0.064 / 0.134$ & \\
\hline & & (4) & (4) & $0.57 / 0.59$ & $0.020 /-0.028$ & $0.008 / 0.044$ & $0.022 / 0.053$ & \\
\hline & Plot 4 & (4) & (4) & $0.05 / 0.05$ & $-0.192 /-0.130$ & $0.065 / 0.060$ & $0.202 / 0.143$ & \\
\hline \multirow[t]{4}{*}{ 2nd_AP } & Plot 1 & (2) & (2) & $0.47 / 0.40$ & $0.017 / 0.006$ & $0.008 / 0.127$ & $0.018 / 0.127$ & Plot 3(2) \\
\hline & Plot 2 & (3) & (3) & $0.93 / 1.00$ & $0.110 / 0.091$ & $0.094 / 0.044$ & $0.144 / 0.101$ & \\
\hline & Plot 3 & (2) & (2) & $0.53 / 0.54$ & $0.009 /-0.014$ & $0.017 / 0.080$ & $0.019 / 0.082$ & \\
\hline & Plot 4 & (1) & (1) & $0.86 / 0.86$ & $0.069 / 0.083$ & $0.012 / 0.113$ & $0.070 / 0.140$ & \\
\hline \multirow[t]{3}{*}{ 2nd_M } & Plot 1 & (2) & (2) & $1.00 / 1.00$ & $0.140 / 0.098$ & $0.077 / 0.057$ & $0.159 / 0.114$ & Plot 3(2) \\
\hline & Plot 2 & (3) & (3) & $0.92 / 0.93$ & $0.132 / 0.083$ & $0.091 / 0.054$ & $0.160 / 0.099$ & \\
\hline & Plot 3 & (2) & (2) & $0.53 / 0.54$ & $0.023 /-0.021$ & $0.041 / 0.040$ & $0.047 / 0.045$ & \\
\hline \multirow[t]{3}{*}{ 3rd_CP } & Plot 1 & (4) & (4) & $0.86 / 0.86$ & $0.081 / 0.091$ & $0.073 / 0.074$ & $0.110 / 0.117$ & Plot 4(3) \\
\hline & Plot 4 & (1) & (1) & $0.93 / 0.93$ & $0.125 / 0.101$ & $0.045 / 0.115$ & $0.133 / 0.153$ & \\
\hline & & (3) & (3) & $0.59 / 0.59$ & $-0.034 /-0.004$ & $0.200 / 0.129$ & $0.203 / 0.130$ & \\
\hline \multirow[t]{7}{*}{ 3rd_AP } & Plot 1 & (2) & (2) & $0.93 / 1.00$ & $0.115 / 0.120$ & $0.068 / 0.053$ & $0.134 / 0.131$ & Plot 3(2) \\
\hline & & (3) & (3) & $0.86 / 0.93$ & $0.085 / 0.114$ & $0.032 / 0.066$ & $0.090 / 0.132$ & \\
\hline & Plot 3 & (2) & (2) & $0.66 / 0.67$ & $0.040 /-0.005$ & $0.028 / 0.055$ & $0.048 / 0.055$ & \\
\hline & & (3) & (3) & $0.79 / 0.79$ & $0.043 /-0.014$ & $0.188 / 0.141$ & $0.192 / 0.142$ & \\
\hline & Plot 4 & (1) & (1) & $0.34 / 0.42$ & $0.005 /-0.042$ & $0.076 / 0.071$ & $0.076 / 0.083$ & \\
\hline & & (3) & (3) & $0.05 / 0.06$ & $-0.156 /-0.042$ & $0.067 / 0.102$ & $0.170 / 0.111$ & \\
\hline & & (4) & (4) & $0.11 / 0.18$ & $-0.148 /-0.045$ & $0.072 / 0.162$ & $0.164 / 0.168$ & \\
\hline \multirow[t]{4}{*}{ 3rd_M } & Plot 1 & (2) & (2) & $1.00 / 1.00$ & $0.145 / 0.143$ & $0.043 / 0.072$ & $0.152 / 0.159$ & Plot 3(2) \\
\hline & & (3) & (3) & $0.86 / 0.86$ & $0.090 / 0.077$ & $0.046 / 0.055$ & $0.101 / 0.090$ & \\
\hline & & (4) & (4) & $0.92 / 0.92$ & 0.088/0.091 & $0.011 / 0.064$ & $0.088 / 0.111$ & \\
\hline & Plot 3 & (2) & (2) & $0.35 / 0.36$ & $-0.025 /-0.036$ & $0.024 / 0.036$ & $0.035 / 0.051$ & \\
\hline
\end{tabular}

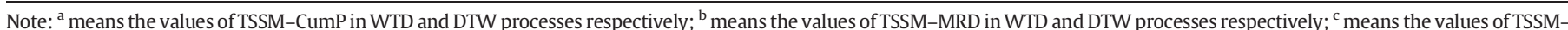

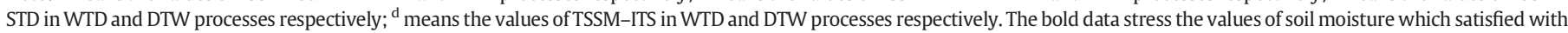

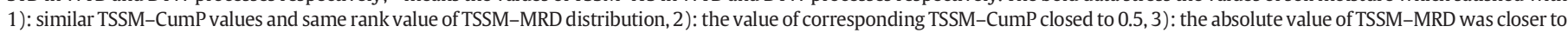
zero; 4): the value of TSSM-ITS to be closer to zero. 
Table 5

Main influencing factors of TSSM characteristics of different microplots during WTD and DTW processes.

\begin{tabular}{|c|c|c|c|c|c|c|c|c|c|}
\hline \multirow[t]{3}{*}{ Position } & \multirow[t]{3}{*}{ Partitions } & \multicolumn{8}{|c|}{ DTW process } \\
\hline & & \multicolumn{2}{|l|}{ Plot 1} & \multicolumn{2}{|l|}{ Plot 2} & \multicolumn{2}{|l|}{ Plot 3} & \multicolumn{2}{|l|}{ Plot 4} \\
\hline & & $\mathrm{HE}$ & HB & $\mathrm{HE}$ & HB & $\mathrm{HE}$ & $\mathrm{HB}$ & $\mathrm{HE}$ & $\mathrm{HB}$ \\
\hline \multirow[t]{3}{*}{$\mathrm{CP}$} & UPG & $x$ & $\times$ & $\mathrm{CS}$ & $\operatorname{Int}(-)$ & CS & Int/Thf $(-/+)$ & $\mathrm{CS}$ & $\operatorname{Int} / \operatorname{Stf} / \operatorname{Thf}(-/+/+)$ \\
\hline & OSF & SS & $\mathrm{RF} / \operatorname{Inf}(-/+)$ & $\mathrm{CS} / \mathrm{SS}$ & $\operatorname{Inf}(+)$ & SS/TNLL/MRS & Inf/Cons $(+/-)$ & SS/TKLL/MRS & $\operatorname{Inf} /$ Cons $(+/-)$ \\
\hline & UDG & SubS & $\operatorname{Inf}(+)$ & SRSD/SubS & $\operatorname{Inf}(+)$ & DRSD/SubS & $\operatorname{Inf}(+)$ & DRSD/SubS & $\operatorname{Inf}(+)$ \\
\hline \multirow[t]{4}{*}{ AP } & UPG & $\times$ & $\times$ & CS & $\operatorname{Int}(-)$ & CS & Int/Thf $(-/+)$ & $\mathrm{CS}$ & Int/Stf/Thf $(-/+/+)$ \\
\hline & OSF & SS & $\mathrm{RF} / \operatorname{Inf}(-/+)$ & $\mathrm{CS} / \mathrm{SS}$ & $\operatorname{Inf}(+)$ & SS/TNLL & $\operatorname{Inf} / \operatorname{Cons}(+/-)$ & SS/TKLL & $\operatorname{Inf} / \operatorname{Cons}(+/-)$ \\
\hline & UDG & SubS & $\operatorname{Inf}(+)$ & SRSD/SubS & $\operatorname{Inf}(+)$ & DRSD/SubS & $\operatorname{Inf}(+)$ & DRSD/SubS & $\operatorname{Inf}(+)$ \\
\hline & & \multicolumn{8}{|c|}{ WTD process } \\
\hline \multirow[t]{3}{*}{$\mathrm{CP}$} & UPG & $\times$ & $\times$ & $\mathrm{CS}$ & $\mathrm{TR}(-)$ & $\mathrm{CS}$ & $\mathrm{TR}(-)$ & CS & $\mathrm{TR}(-)$ \\
\hline & OSF & SS & $\mathrm{EV}(-)$ & $\mathrm{CS} / \mathrm{SS}$ & $\mathrm{EV}(-)$ & SS/TNLL/MRS & $\mathrm{EV} /$ Cons $(-/+)$ & SS/TKLL/MRS & $\mathrm{EV} /$ Cons $(-/+)$ \\
\hline & UDG & SubS & $\times$ & SRSD/SubS & Asm/HL(-/?) & DRSD/SubS & Asm/HL(-/?) & DRSD/SubS & Asm/HL $(-/ ?)$ \\
\hline \multirow[t]{3}{*}{ AP } & UPG & $\times$ & $\times$ & CS & $\mathrm{TR}(-)$ & $\mathrm{CS}$ & $\mathrm{TR}(-)$ & $\mathrm{CS}$ & $\operatorname{TR}(-)$ \\
\hline & OSF & SS & $\mathrm{EV}(-)$ & $\mathrm{CS} / \mathrm{SS}$ & $\mathrm{EV}(-)$ & SS/TNLL & $\mathrm{EV} /$ Cons $(-/+)$ & SS/TKLL & $\mathrm{EV} /$ Cons $(-/+)$ \\
\hline & UDG & SubS & $\times$ & SRSD/SubS & $\operatorname{Asm} / \mathrm{HL}(-/ ?)$ & DRSD/SubS & $\operatorname{Asm} / \mathrm{HL}(-/ ?)$ & DRSD/SubS & Asm/HL $(-/ ?)$ \\
\hline
\end{tabular}

Note: HE: hydrological environment; HB: hydrological behavior; UG: upon the ground; OSF: on the surface; UDG: under the ground.

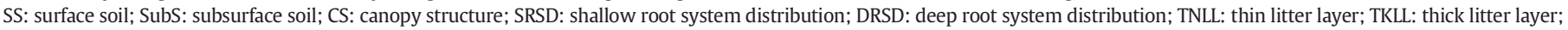
MRS: main root system.

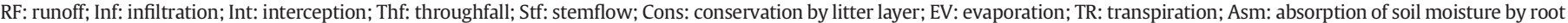
system distribution; HL: hydrological lift.

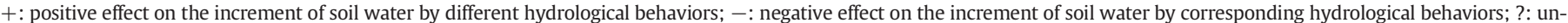
known effect on the increment of soil water by hydrological lift.

4) having more obvious porous structures in the CP area, under relatively low precipitation conditions-such as the rainfall events in 2011, there existed more water infiltration to deeper soil layers, making the surface soil moisture in plot 4 lower than that of the other microplot types. However, with the increased of frequency and amount of rainfall in 2012, the higher porosity structure in the CP areas of plot 4 could retain more moisture than other microplots on the soil surface when the soil was under saturated conditions. On the other hand, throughout the WTD processes, evapotranspiration was one of the fundamental patterns of soil moisture loss on the ground. Therefore, it led the vegetation types such as plot 3 and plot 4 to have a higher rate of water loss and caused these two vegetation types to have significant lower surface soil moisture than the bare land. This study was also similar to Wang et al. (2012) who systematically analyzed the soil moisture of five different revegetation types that were impacted by the evapotranspiration in the Loess Plateau. And this huge consumption of water resources by vegetation could potentially cause the formation of a drier layer in the Loess Plateau (Chen et al., 2008a, 2008b, 2010; Wang et al., 2012, 2013).

Secondly, in the AP area, rather than a part of the soil crust being distributed on the surface of plot 1 , indicated in Table 2, the obvious crown structure and different thickness litter layers covering the surface as well as the root system distribution of plot 3 and plot 4, could play a complicated role in intercepting precipitation (Rodriguez-Iturbe et al., 2001) retaining water resources (Porporato et al., 2001) and finally preventing soil erosion (Gyssels et al., 2005) throughout whole WTD processes. Moreover, throughout the DTW processes, due to the positive correlation between the canopy structure and the thresholds of rainfall interception (Laio et al., 2001), a wider average crown above the AP area of plot 4 , could lead this vegetation type to have a lower probability of receiving intermittent throughfall than plot 3; meanwhile, the thicker litter layer covering on plot 4 probably has a greater ability than plot 3 to retain through fall on the soil surface and to prevent water from entering the soil medium. Therefore, during the water input processes, both of the crown and litter layer characteristics lead to the significant lower soil moisture in the AP areas than other vegetation types. In addition, Villegas et al. (2010) explored the hierarchical effects the of litter layer on restricting the evaporation of the surface soil moisture, although in our study, the litter layers' ecohydrological ability of soil evaporation control (Villegas et al., 2010) in the AP area seemed to be less than the water consumption through evapotranspiration especially triggered by high temperature weather conditions, which finally, cause the vegetation types to have a significantly lower soil water content than that of bare land in the AP area throughout the WTD processes.

\subsection{Representative soil moisture point distribution in the $C P / A P S$}

Representative soil moisture point that represented the greatest temporal stability point of all of the moisture measuring points was derived from the consideration of the spatial optimized sampling scheme (Grayson and Western, 1998). Based on the TSSM analysis calculation system, the representative soil moisture reflects the spatial mean soil water content in the corresponding study area. Previous researchers (Martinez-Fernandez and Ceballos, 2003; Van Pelt and Wierenga, 2001) mainly focused on the representative points at the catchment scale, or even larger spatial scales. Penna et al. (2013) downscaled the spatial scale to hillslopes and determined the representative points of different soil depths. However, in our study, by further downscaling the representative point to single vegetation scale, we combined hydrological response with determination of the representative point distribution in the CP/APs' areas of different vegetation types and bare land cover, which could more effectively explore and comprehend the TSSM information as well as its influencing factors over the whole WTD and DTW processes (Lin et al., 2006). In Table 4 the representative point determination system indicated that, over DTW and WTD processes in two rainy season, TSSM characteristics in the low shrub types (plot 3 ) at the AP, CP and microplot scales, illuminated that the soil moisture in plot 3 could represent the spatial average soil moisture of the hillslope on which the heterogeneity vegetation types and bare land cover were distributed. In our study, the vegetation type (plot 3) characterized as the highest TSSM type could be regarded as the representative soil moisture types in all microplots, which, however, was seemed to be different from the research of Gomez-Plaza et al. (2000) who indicated that the vegetation increased the temporal fluctuation of soil moisture. And the difference was probably related to the different researching scales. Specifically, Gomez-Plaza et al. (2000) mainly focused on the soil moisture representative point at the catchment scale, but we mainly stressed the representative points at a plant scale by integrating the ecohydrological information with the corresponding TSSM characteristics under heterogeneous vegetation. Generally, Table 5 concluded all the possible influencing factors of TSSM characteristics in the four microplot types, and these factors existing in different hydrological environments and generating various hydrological behaviors also 


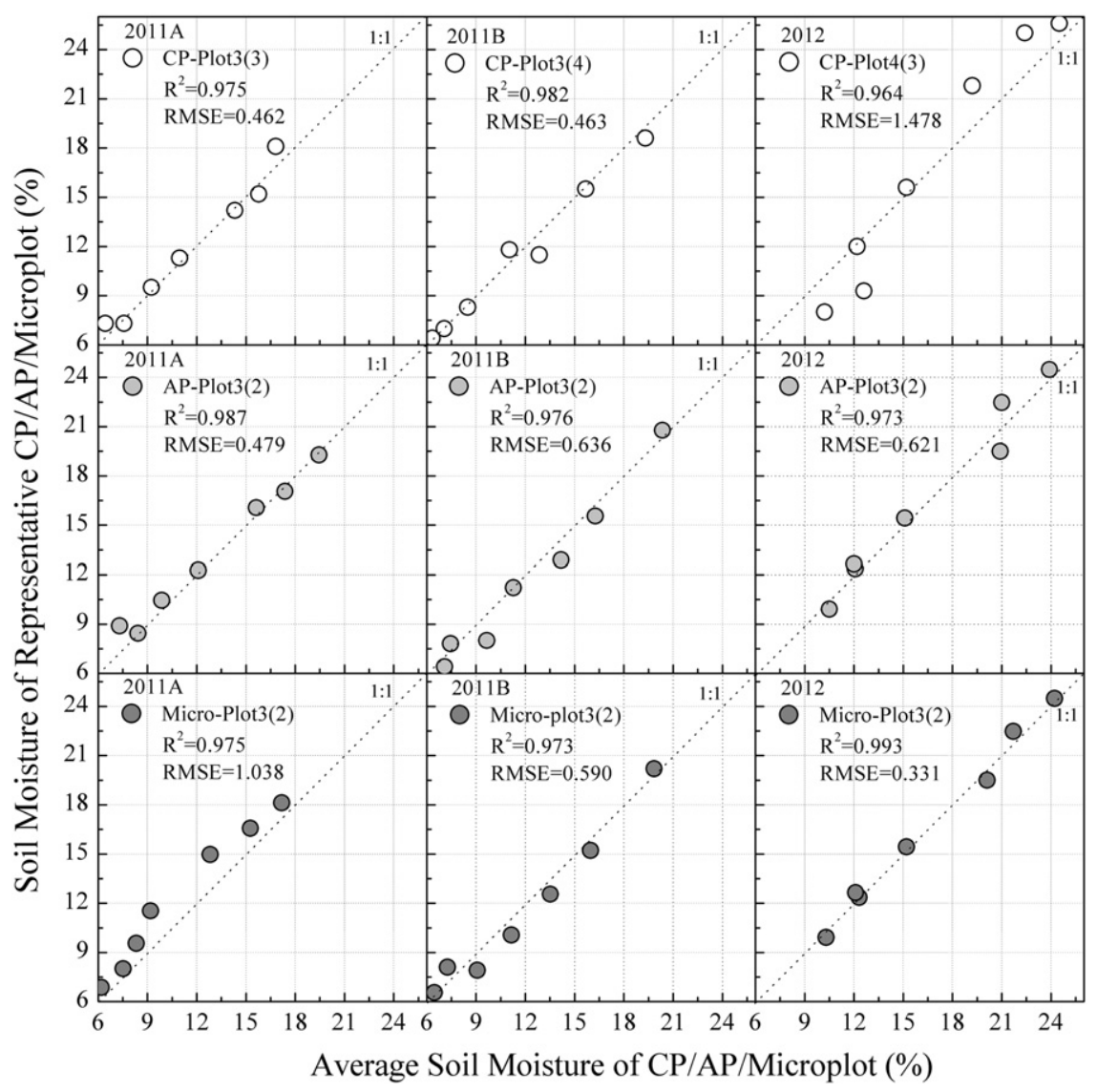

Fig. 11. Comparison of average soil moisture and representative soil moisture at AP, CP and microplot scales.

played the key roles in determining the representative points which reflected the mean soil water content in a specific hillslope during WTD and DTW processes. Compared with the bare land cover (plot 1), grass land (plot 2), and high shrub (plot 4), the complexity of the influencing factors-including morphological characteristics above the ground and soil surface properties affected by litter layer in the low shrub microplot (plot 3)-may be moderate and the corresponding hydrological function leads to the highest TSSM in all of the microplots, which caused plot 3 to have the best representativeness of the average soil moisture. Specifically, the hydrological response in plot 3 throughout the precipitation and radiation periods was more complex than that of plot 1 and plot 2. Because, in plot 3, the canopy structure, litter layer and the deep root system all respectively played different roles in redistributing the input and output patterns of water resources (Li et al., 2009). However, in plot 1 and plot 2, similar to some researchers' view (Gomez-Plaza et al., 2000; Jacobs et al., 2004) the soil hydrological conductivity, soil curst, probably became the main influencing factors of water resource distribution. According to some studies (Garcia-Estringana et al., 2010; Levia and Frost, 2003), the obvious stem structure in plot 4 could have high probability to generate the stemflow which would cause plot 4 to be more regarded as a precipitation collection system (Li, 2011) than plot 3 in arid and semi-arid ecosystems. Additionally, the more complex hydrological behavior in root-soil interface environment of plot 4-such as the preferential flow (Li et al., 2009), plant hydraulic lift, and the dynamics between the soil water potential and the xylem osmotic (press) potential (Porporato et al., 2001) - could also cause the corresponding soil moisture to experience stronger temporal fluctuant process than plot 3. Furthermore, in Fig. 11, the linear regression analysis and root mean square error (RMSE) calculation was used to test the representativeness of soil moisture in plot 3 through comparing its soil moisture with the average soil moisture of all microplots. And the figure also indicated that the soil moisture in plot 3 could be the best choice of representative soil moisture point in the CP, AP as well as in microplot scales over the WTD and DTW processes. In addition, as to the influence of $\mathrm{CP} / \mathrm{APs}$ sampling method on the measurement results, the disturbance of the soil layer during the soil moisture measurement processes-including designating the $\mathrm{CP} / \mathrm{APs}^{\prime}$ sampling circle areas, removing and recovering the litter layer condition as well as mending the disturbing hole-also inevitably brought system error into the analysis of the TSSM characteristic and the determination of the representative points. It was similar to the discussion of Zhao et al. (2010) who indicated that inaccurate measurement could cause errors in the TSSM analysis, and the fixing soil-moisturemeasuring tubes (Jost et al., 2012) into the soil layer could be an efficient method to reduce errors in future studies.

\section{Conclusions}

In this study, we used the hydrological-trait soil moisture sampling method to analyze the temporal persistence characteristics of the soil moisture as well as to determinate the representative soil moisture points in heterogeneous vegetation and bare microplot distribution on a hillslope of the Loess Plateau, China. And the main conclusions can be summarized as follows: precipitation and the duration of high temperature conditions could impact the soil moisture of different microplots throughout the DTW and WTD processes. The soil moisture of different microplots at the same sampling points ( $\mathrm{AP}$ or $\mathrm{CP}$ ) indicated significant difference under WTD or DTW processes. And the soil moisture in tall shrub microplots (plot 4) tended to be lower than other three types. The TSSM of the low shrub microplots (plot 3) at the AP, CP and microplots scales seemed to be higher than that of the other vegetation types. In the CP area, the TSSM of the vegetation types tended to decreased over whole WTD processes, although, at the end of the WTD process, the degree of the temporal fluctuation of soil moisture in the 
vegetation microplots in the AP area tended to decrease. Based on TSSM-MRD/STD/ITS/CumP analysis as well as the RMSE test, the plot 3 could be regarded as the representative point at the AP, CP and microplot scales, which represented the spatial mean soil water content of the heterogeneous vegetation types and bare land cover. The study on TSSM of different vegetation types supplemented the soil moisture temporal properties affected by vegetation types, and could be beneficial to understanding how to design the vegetation layout to reasonably use the available water resources in a water-limited ecosystem.

\section{Acknowledgments}

This work was funded by the National Natural Science Foundation of China (Nos. 41390464 and 41101096). We also appreciate the editor and anonymous reviewers' supports and comments.

\section{References}

Bell, K.R., Blanchard, B.J., Schmugge, T.J., Witczak, M.W., 1980. Analysis of surface moisture variations within large field sites. Water Resour. Res. 16, 798-810.

Biswas, A., Si, B.C., 2011. Scales and locations of time stability of soil water storage in a hummocky landscape. J. Hydrol. 408, 100-112.

Brocca, L., Morbidelli, R., Melone, F., Moramarco, T., 2007. Soil moisture spatial variability in experimental areas of central Italy. J. Hydrol. 333, 356-373.

Brocca, L., Melone, F., Moramarco, T., Morbidelli, R., 2009. Soil moisture temporal stability over experimental areas in Central Italy. Geoderma 148, 364-374.

Brocca, L., Melone, F., Moramarco, T., Morbidelli, R., 2010. Spatial-temporal variability of soil moisture and its estimation across scales. Water Resour. Res. 46, W02516. http://dx.doi.org/10.1029/2009WR008016/pdf.

Caldwell, M.M., Dawson, T.E., Richard, J.H., 1998. Hydraulic lift consequences of water efflux from the roots of plants. Oecologia 113, 151-161.

Calvo-Cases, A., Boix-Fayos, C., Imeson, A.C., 2003. Runoff generation, sediment movement and soil water behavior on calcareous (limestone) slopes of some Mediterranean environments in southeast Spain. Geomorphology 50, 269-291.

Chen, H., Shao, M., Li, Y., 2008a. Soil desiccation in the Loess Plateau of China. Geoderma $143,91-100$.

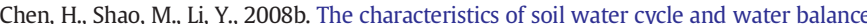
on steep grassland under natural and simulated rainfall conditions in the Loess Plateau of China. J. Hydrol. 360, 242-251.

Chen, L., Wang, J., Wei, W., Fu, B., Wu, D., 2010. Effects of landscape restoration on soil water storage and water use in the Loess Plateau Region, China. For. Ecol. Manag. 259, 1291-1298

Coppola, A., et al., 2011. Average moisture saturation effects on temporal stability of soil water spatial distribution at field scale. Soil Tillage Res. 114, 155-164.

Cosh, M.H., Jackson, T.J., Starks, P., Heathman, G., 2006. Temporal stability of surface soi moisture in the Little Washita River watershed and its applications in satellite soi moisture product validation. J. Hydrol. 323, 168-177.

Dawson, T.E., 1993. Hydraulic lift and water use by plants: implication for water balance performance and plant-plant interaction. Oecologia 95, 565-574.

Eagleson, P.S., 1978a. Climate, soil and vegetation 1. Introduction to water balance dynamics. Water Resour. Res, 14, 705-712.

Eagleson, P.S., 1978b. Climate, soil and vegetation 2. The distribution of annual precipitation derived from observed storm sequences. Water Resour. Res. 14, 713-721.

Eagleson, P.S., 1978c. Climate, soil and vegetation 4. The expected value of annua evapotranspiration. Water Resour. Res. 14, 731-739.

Fitzjohn, C., Ternan, J.L., Williams, A.G., 1998. Soil moisture variability in a semi-arid gully catchment: implications for runoff and erosion. Catena 32, 55-70.

Gao, L., Shao, M., 2012. Temporal stability of soil water storage in diverse soil layers. Catena 95, 24-32.

Gao, G.Y., et al., 2012. Coupling the modified SCS-CN and RUSLE models to simulate hydrological effects of restoring vegetation in the Loess Plateau of China. Hydrol Earth Syst. Sci. 16, 2347-2364

Garcia-Estringana, P., Alonso-Blázquez, N., Alegre, J., 2010. Water storage capacity, stemflow and water funneling in Mediterranean shrubs. J. Hydrol. 389, 363-372.

Gomez-Plaza, A., Alvarez-Rogel, J., Alabaladejo, J., Castillo, V.M., 2000. Spatial patterns and temporal stability of soil moisture across a range of scales in a semi-arid environment. Hydrol. Process. 14, 1261-1277.

Grayson, R.B., Western, A.W., 1998. Toward areal estimation of soil water content from point measurement: time and space stability. J. Hydrol. 207, 68-82.

Grayson, R.B., Western, A.W., Chiew, F.H.S., 1997. Preferred states in spatial soil moisture patterns: local and no local control. Water Resour. Res. 33, 2897-2908.

Gyssels, G., Poesen, J., Bochet, E., Li, Y., 2005. Impact of plant roots on the resistance of soils to erosion by water: a review. Prog. Phys. Geogr. 29, 189-217.

Hartanto, H., Prabhu, R., Anggoro, S.E., Asdak, C., 2003. Factors affecting runoff and soil erosion: plot-level soil loss monitoring for assessing sustainability of forest management. For. Ecol. Manag. 180, 361-374.

Heathman, G.C., Cosh, M.H., Eunjin, Han, Jackson, T.J., McKee, L., McAfee, S., 2012. Field scale spatiotemporal analysis of surface soil moisture for evaluating point-scale in situ networks. Geoderma 170, 195-205.
Horton, J.L., Hart, S.C., 1998. Hydraulic lift: a potentially important ecosystem process. Tree $13,232-235$

Hu, W., Shao, M., Han, F., Reichardt, K., Tan, J., 2010. Watershed scale temporal stability of soil water content. Geoderma 158, 181-198.

Jacobs, J., Mohanty, B.P., Hsu, E.C., Miller, D., 2004. SMEX02: field scale variability, time stability and similarity of soil moisture. Remote Sens. Environ. 92, 436-446.

Jia, Y.H., Shao, M.A., 2013. Temporal stability of soil water storage under four types of revegetation on the northern Loess Plateau of China. Agric. Water Manag. 117, $33-42$

Jost, G., Schume, H., Hager, H., Markart, G., Kohl, B., 2012. A hillslope scale comparison of tree species influence on soil moisture dynamics and runoff processes during intense rainfall. J. Hydrol. 420-421, 112-124.

Kachanoski, R.G., de Jong, E., 1988. Scale dependence and the temporal stability of spatial patterns of soil water storage. Water Resour. Res. 24, 85-91.

Laio, F., Porporato, A., Ridolfi, L., Rodriguez-Iturbe, I., 2001. Plant in water-controlled ecosystems; active role in hydrologic processes and response to water stress: II. Probabilistic soil moisture dynamics. Adv. Water Resour. 24, 707-723.

Levia, D.F., Frost, E.E., 2003. A review and evaluation of stemflow literature in the hydrologic and biogeochemical cycles of forested and agricultural. J. Hydrol. 274, 1-29.

Li, X.Y., 2011. Mechanism of coupling, response and adaptation between soil, vegetation and hydrology in arid and semiarid regions (in Chinese). Sci. Sin. Terrae 41, $1721-1730$

Li, Y., Poesen, J., Yang, J.C., Fu, B., Zhang, J.H., 2003. Evaluating gully erosion using ${ }^{137} \mathrm{Cs}$ and ${ }^{210} \mathrm{~Pb} /{ }^{137} \mathrm{Cs}$ ratio in a reservoir catchment. Soil Tillage Res. 69, 107-115.

Li, X.Y., Yang, Z.P., Li, Y.T., Lin, H., 2009. Connecting ecohydrology and hydropedology in desert shrubs: stemflow as a source of preferential flow in soils. Hydrol. Earth Syst. Sci. $13,1133-1144$

Lin, H.S., Kogelmann, W., Walker, C., Bruns, M.A., 2006. Soil moisture patterns in a forest catchment: a hydropedological perspective. Geoderma 131, 345-368.

Martinez-Fernandez, J., Ceballos, A., 2003. Temporal stability of soil moisture in a large field experiment in Spain. Soil Sci. Soc. Am. J. 67, 1647-1656.

Matinez, G., Pachepsky, Y.A., Vereecken, H., 2014. Temporal stability of soil water content as affected by climate and soil hydraulic properties: a simulation study. Hydrol. Process. 28, 1899-1915.

Mittelbach, H., Seneviratne, S.I., 2012. A new perspective on the spatio-temporal variability of soil moisture: temporal dynamics versus time-invariant contributions. Hydrol. Earth Syst. Sci. 16, 2169-2179.

Mohanty, B.P., Skaggs, T.H., 2001. Spatio-temporal evolution and time-stable characteristics of soil moisture within remote. Adv. Water Resour. 24, 1051-1067.

Noy-Meir, I., 1973. Desert ecosystems: environment and producers. Annu. Rev. Ecol. Syst. $4,25-51$.

Penna, D., Brocca, L., Borga, M., Dalla, F.G., 2013. Soil moisture temporal stability at different depths on two alpine hillslopes during wet and dry periods. J. Hydrol. 477, 55-71.

Porporato, A., Laio, F., Ridolfi, L., Rodriguez-Iturbe, I., 2001. Plant in water-controlled ecosystems: active role in hydrologic processes and response to water stress: III. Discussion of real cases. Adv. Water Resour. 24, 725-744.

Porporato, A., D'Odorico, P., Laio, F., Ridolfi, L., Rodriguez-Iturbe, I., 2002. Ecohydrology of water-controlled ecosystems. Adv. Water Resour. 25, 1335-1348.

Qiu, Y., Fu, B., Wang, J., Chen, L., 2001. Soil moisture variation in relation to topography and land use in a hillslope catchment of the Loess Plateau. J. Hydrol. 240, 243-263.

Rodriguez-Iturbe, I., Porporato, A., Laio, F., Ridolfi, L., 2001. Plant in water-controlled ecosystems: active role in hydrologic processes and response to water stress I. Scope and general outline. Adv. Water Resour. 24, 695-705.

Shao, M.A., Guo, Z.S., Xia, Y.Q., Wang, Y.P., 2010. Study on the Carrying Capacity of Vegetation for Soil Moisture in the Loess Plateau of China. Science Press, Beijing.

Starks, P.J., Heathman, G.C., Jackson, T.J., Cosh, M.H., 2006. Temporal stability of soil moisture profile. J. Hydrol. 324, 400-411.

Vachaud, G., Passerat De Silans, A., Balabanis, P., Vauclin, M., 1985. Temporal stability of spatially measured soil water probability density function. Soil Sci. Soc. Am. J. 49, 822-828.

Van Pelt, R.S., Wierenga, P.J., 2001. Temporal stability of spatially measured soil water matric potential probability density. Soil Sci. Soc. Am. J. 65, 667-668

Villegas, J.C., Breshears, D.D., Zou, C.B., Law, D.J., 2010. Ecohydrological controls of soil evaporation in deciduous drylands: how the hierarchical effects of litter, patch and vegetation mosaic cover interact with phenology and season. J. Arid Environ. 74, 595-602.

Wang, Y.F., Fu, B.J., Chen, L.D., Lu, Y.H., Luo, C.Y., 2009. Effects of land use change on soil erosion intensity in small watershed of Loess Hilly Region: a quantitative evaluation with 137-Cesium tracer (in Chinese). Chin. J. Appl. Ecol. 20, 1571-1576.

Wang, S., Fu, B.J., Gao, G.Y., Yao, X.L., Zhou, J., 2012. Soil moisture and evapotranspiration of different land cover types in the Loess Plateau, China. Hydrol. Earth Syst. Sci. 16, 2883-2892.

Wang, S., Fu, B.J., Gao, G.Y., Liu, Y., Zhou, J., 2013. Responses of soil moisture in different land cover types to rainfall events in a re-vegetation catchment area of the Loess Plateau, China. Catena 101, 122-128.

Williams, C.J., McNamara, J.P., Chandler, D.G., 2009. Control on the temporal and spatial variability of soil moisture in a mountainous landscape: the signature of snow and complex terrain. Hydrol. Earth Syst. Sci. 13, 1336-1352.

Zhao, Y., Peth, S., Wang, X.Y., Lin, H., Horn, R., 2010. Control of surface soil moisture spatial patterns and their temporal stability in a semi-arid steppe. Hydrol. Process. 18, 2507-2519. 